\title{
INVENTION ET ÉLABORATION D'UNE TRADITION SAINT ELDRAD, CITOYEN ET PATRON DE LAMBESC (BOUCHES-DU-RHÔNE) *
}

Les raisons de la diffusion d'une dévotion sont parfois difficiles à comprendre. On le voit avec l'explosion à la Réunion du culte de saint Expédit, personnage d'authenticité douteuse, que l'on explique parfois par l'arrivée d'une caisse de reliques envoyée de Rome sur laquelle l'étiquette d'envoi déchirée ne comportait plus que le mot «espedito » et la date d'envoi. Ingénieux, mais sans doute trop beau pour être vrai ! En revanche, les modalités de l'introduction au XVIII ${ }^{\mathrm{e}}$ siècle dans une bourgade de basse Provence du culte de saint Eldrad, abbé au $\mathrm{Ix}^{\mathrm{e}}$ siècle d'un monastère proche du Mont-Cenis, de son intronisation comme citoyen, seigneur et patron de ce lieu, et de la persistance de cette croyance jusqu'à nos jours, pour surprenantes qu'elles soient, peuvent être retracées avec certitude. Il a fallu la découverte d'une lettre comme tombée du ciel, les contre-sens d'un feuillant savoyard, la crédulité d'un curé de village, l'imagination romanesque d'un maire de la Restauration et le travail incessant de pseudo-érudits locaux pour élaborer et enrichir sans cesse une tradition désormais aussi tenace que celle de l'apostolicité des Églises de Provence.

\section{Un patronage tardif}

Une récente publication a regroupé fort commodément en un seul volume les réponses adressées par les maires des communes du département des Bouches-du-Rhône à un des points du questionnaire que le préfet Christophe de Villeneuve-Bargemon leur avait adressé le 5 février 1825 en vue de la publication du tome II de la Statistique du département des Bouches-duRhône qu'il se disposait à publier ${ }^{1}$. Le préfet souhaitait que fût précisé le

* Je tiens à remercier Brigitte Lam, Claire Laurent, Claudine Pezeron, Régis Bertrand, Jean-Paul Boyer, le docteur Cardin, Christian Davaine, Marc Heijmans, Pierre-Yves Playoust et Laurent Ripart pour le concours qu'ils m'ont apporté dans cette enquête.

1. François Gasnault, Pierre Gombert, Félix Laffé et Jacqueline Ursch (dir.), Récits de fêtes en Provence au XIX siècle : le préfet statisticien et les maires ethnographes, Milan/ [Marseille], 2010. 
calendrier des fêtes célébrées dans chaque localité. Le maire du village de Lambesc, Jacques Martin-Jaubert, répond que « la fête de saint Michel est la patronale ", mais qu' " on y célèbre aussi solennellement le 13 mars la fête de saint Eldrad, abbé de Novalèse, seigneur et citoyen de Lambesc, dont on conserve quelques reliques " ${ }^{2}$. L'existence de cette seconde fête quasi patronale est surprenante. On ne trouve en effet aucune mention de ce saint et de son culte à Lambesc dans les sources qui reflètent la vie religieuse du village ${ }^{3}$.

Les premiers documents conservés relatifs aux sanctuaires de Lambesc mentionnent, vers 940, une église Saint-Victor et, en janvier 1053, les églises Sainte-Marie, Saint-Pierre et Saint-Jean-Baptiste ${ }^{4}$. De la même période datent des sanctuaires sous le vocable de Saint-Michel et de la Trinité ${ }^{5}$. Aux $\mathrm{xv}^{\mathrm{e}}$ et $\mathrm{xvI} \mathrm{I}^{\mathrm{e}}$ siècles, l'église paroissiale porte le vocable de Saint-Michel, et dans le terroir s'élèvent des chapelles dédiées à saint Victor, aux saints Gervais et Protais, puis, à partir du Xvi ${ }^{\mathrm{e}}$ siècle, à sainte Catherine, à saint Siffrein et, un peu plus tard, à saint Étienne. Dans la seconde moitié du xvi e siècle, l'église Saint-Michel, qui se situe hors les murs, cesse d'être le siège de la paroisse. Une nouvelle église paroissiale est bâtie au cœur du village, qui prend le nom de Notre-Dame-de-la-Rose. Le 8 décembre 1699, le conseil de ville décide de remplacer sur le même site cette église jugée exiguë et qui menace ruine, et de bâtir, sur le même emplacement et sous le même vocable, un édifice plus grand, dont la construction commence dès l'année suivante ${ }^{6}$.

À partir du milieu du xvI ${ }^{\mathrm{e}}$ siècle, les procès-verbaux de visites pastorales dressent la liste des autels et des saints auxquels ils sont dédiés. La visite de 1424 mentionnait uniquement un autel de Saint-Sébastien, que l'on retrouve en 1552 et qui est cité jusqu'à la visite de 1627. Figurent également les saints Jacques $(1552,1676)$, Antoine $(1552,1619,1627)$, Martin $(1552,1619,1676)$, Côme et Damien (1619), Jean-Baptiste (1619 et 1689), Éloi (1619, 1627), Pierre (1619), Maurice (1619), Marc (1627), Martin (1676), Blaise (1676) et Symphorien (1676). La visite de 1676 affirme à deux reprises, à propos d'un autel et d'un tableau qui lui sont consacrés, que saint Michel est «patron de ce lieu » ou "patron de la paroisse ». Saint Joseph apparaît seulement lors la visite de 1689, qui ne dénombre pas les autels, mais dresse la liste des chapelles. Parmi les registres des confréries qui ont été conservés figure bien celui de la confrérie de Saint-Joseph, mais il commence un peu plus tard (1745) que celui

2. Ibid., p. 232. Le nom du saint est orthographié de multiples façons par les différents auteurs qui traitent de sa vie : "Eldra », "Eldrad », "Eldrade », "Eldradus », "Heldrad », «Oldra », "Idra »... J'ai respecté les graphies propres aux textes cités, et adopté dans ma rédaction la forme "Eldrad », la plus voisine du latin Eldradus.

3. Voir Arch. dép. des Bouches-du-Rhône, 1 G 201 bis (1421) et ter (1424-1425), 1332 (1535 et 1619), 1334 (1627), 1341 (1676) et 1343 (1689).

4. Cartulaire de l'abbaye de Saint-Victor de Marseille, éd. Benjamin Gú́rard, Paris, 1857 (Coll. de documents inédits sur l'histoire de France. Première partie : Histoire politique. Coll. des cartulaires de France, 8), vol. I, n ${ }^{\circ} 23$, p. 28-30, et Estelle Bcur, Le chartrier de l'archevêché d'Arles (417-1202), thèse pour le diplôme d'archiviste paléographe, 1996, dactyl., nº 20, p. 43.

5. Voir Christian Heck, «Implantation religieuse et renouveau des campagnes en Provence, du XI ${ }^{\mathrm{e}}$ au XIII ${ }^{\mathrm{e}}$ siècle : la région de Lambesc", dans Archéologie médiévale, t. 5 (1975), p. 54.

6. Jean Boyer, "L'église de Lambesc ", dans Congrès archéologique de France, $143^{e}$ session (1985), Le pays d'Aix, Paris, 1988, p. 190-215. 
de la confrérie de Saint-Eldrad (1743), qui est le premier témoignage de l'existence de cette dévotion dans le village ?

\section{La révélation}

C'est effectivement en 1743, le 13 mars, que saint Eldrad fait son entrée à Lambesc, comme le rapportent les premiers feuillets du registre de la confrérie, sous un titre en gros caractères : "Entrée du glorieux saint Eldra, ancien seigneur de Lambesc, religieux de l'ordre de Saint-Benoît et abbé de la Novalaise, située au pied du Mont-Cenis ${ }^{8}$." Il y est expliqué par quel concours de circonstances le culte de ce saint fut introduit dans le village, à une date que le document ne précise pas, mais que l'on peut situer à l'extrême fin du xviI ${ }^{\mathrm{e}}$ siècle ${ }^{9}$ :

«La divine providence fit tomber entre les mains de messire François Aubert, prêtre, bachelier en sainte théologie, curé perpétuel de l'église doyene de la ville de Lambesc, il y a quelques années, la copie d'une lettre écritte de la Novalaise à feu M. le comte de Grignan, lieutenant pour le roy en cette province ${ }^{10}$, par le révérend père don Rochez, de la congrégation réformée de Saint-Bernard ${ }^{11}$, par laquelle ce religieux lui aprenoit le dessein qu'il avoit de donner au public la vie de saint Eldra, des anciens seigneurs de Lambesc en Provence et abbé de la Novalaise ${ }^{12}$. "Nous lisons dans nos croniques, disoit-il dans sa lettre en datte du $8^{\text {me }}$ octobre 1669 , que saint Eldra, seigneur de Lambesc, arriva au commencement du huitième siècle au monastère de la Novalaise pour être receu au nombre des moines. Il fut admis au novitiat, et, après sept années d'exercice dans la piété monastique, ses rares vertu [sic] et son mérite distingué l'élevèrent à la première dignité de l'abbaye. La sainteté de sa mort

7. Arch. dép. des Bouches-du-Rhône, 129 E GG 7 (registre de la confrérie de Saint-Eldrad) et 12 (registre de la confrérie de Saint-Joseph).

8. Arch. dép. des Bouches-du-Rhône, 129 E GG 7, fol. 3r.

9. Le chanoine Firmin Ollivier, dans son opuscule Histoire de mon pays, Lambesc, jadis " terre lorraine ", s. l. n. d. [après 1936], affirme, sans fournir aucune preuve, que "la lettre de dom Rocher reste à la mairie de Lambesc, où on la trouva en 1741 ». Mais le récit qui figure dans le registre de la confrérie date du 3 mars 1700 la réponse de l'abbé de la Novalaise à la lettre du curé de Lambesc faisant suite à la découverte de la lettre de dom Rochex. Ce nom aussi est orthographié de différentes façons dans les sources.

10. François-Adhémar de Monteil, comte de Grignan, lieutenant général du roi en Provence de 1669 à 1714 .

11. Selon Eugène Manning, Jean de Saint-Louis Rocher, feuillant, est entré à l'abbaye NotreDame du Teston en 1632 (Eugène Manning, article " Rocher (Jean de Saint-Louis) », dans Émile Brouette, Anselme Dimier et E. Manning (dir.), Dictionnaire des auteurs cisterciens, t. II, fasc. 3, Rochefort, 1978 (La documentation cistercienne, 16), col. 619). Le même auteur donne pour le livre de ce religieux un titre erroné : «[Il] écrivit L'histoire de l'abbaye de la Novalèse, ouvrage qui fut imprimé à Chambéry en 1670 " (ibid.). Le nom de cet auteur tel qu'il figure en tête de ce livre est " Rochex ", et le registre de la confrérie de Saint-Eldrad l'orthographie " Rochez ". L'abbaye dans laquelle il entre est Santa Maria di Testona, près de Moncalieri. Cela fait beaucoup d'erreurs et d'approximations en quelques lignes.

12. Dom Rochex achève alors la préparation de son livre La gloire de l'abbaye et vallée de la Novalese, située au bas du Montcinis, du côté d'Italie, ensemble un discours de la Savoie et de la ville de Chambery, sa capitale, de son ancienneté et de plusieurs autres regions, enrichi de quantité de remarques curieuses et louables tirées de divers autheurs, tant anciens que modernes, qui paraîtra à Chambéry en 1670. Cette lettre, postérieure à la nomination du comte de Grignan comme lieutenant général de Provence et antérieure à la parution de l'ouvrage qu'elle annonce, ne peut être datée que de 1669. 
répondit à la saintetté de sa vie, et à son intercession plusieurs grands miracles furent opérés depuis ce tems-là en faveur de ceux qui se recommandoient à saint Eldra." Ce bon religieux finissoit sa lettre en priant M. de Grignan d'avoir la bonté, lorsqu'il iroit à Lambesc pour l'assemblée des états de la province ${ }^{13}$, de lui procurer des mémoires sur la famille de saint Eldra, s'il en restoit encore quelques traces dans sa patrie, pour les insérer dans son histoire.

«La lecture de cette lettre lui donna lieu d'approfondir si elle contenoit véritté. Pour y parvenir, il écrivit au supérieur du couvent de la Novalaise, et, en lui exposant en peu de mots le fait, il lui demanda sur cela des éclaircissements. Il le pria en même tems de lui procurer une petitte portion des reliques de saint Eldra. [...] Le supérieur du monastère répondit à sa lettre d'une manière fort polie. Sa réponse est en datte du $3^{\text {me }}$ mars 1733. Il lui donna tous les éclaircissements qu'il lui demanda, et il eut même la précaution de lui envoyer la légende de l'office de saint Eldra approuvée par un bref de la Congrégation des cardinaux du $6^{\mathrm{e}}$ octobre 1701. Il fit plus : il lui fournit des moyens pour recouvrer le livre que le père don Rochez avoit fait imprimer à Chambéry touchant la vie de saint Eldra ${ }^{14}$."

Le livre de dom Rochex apporta au curé Aubert la confirmation de l'origine lambescaine de saint Eldrad :

«Ce glorieux saint Eldra, ou Oldra, fut de nation françoise, de la province de Provence, nay de parens nobles, riches et puissans seigneurs du château et mandement de Lambelli, soit Lambellées, et d'autres disent Lambées, château fort, situé près le fleuve de Deranse ou Dranse, elevé sur un cousteau qui est encore à present en existence, à ce que l'on m'en a asseuré ${ }^{15}$. "

L'auteur reproduisait plus loin le texte original tel qu'il l'a lu dans les archives de l'abbaye :

"Beatus Eldradus, ex Gallicana patria quae dicitur Provincia, non infimis parentibus ortus et, ut acertum dicatur, Ambolianensis oppidi, Alpinis montibus undique cepti, municeps, et indigena fuit nobilis quidem genere, sed nobilior animi virtute. Ex Ambelli castello Galliae inter Alpes ortus Provinciae prope flumen Dederausum ${ }^{16}$."

On le voit avec cette amplification qui traduit «non infimis parentibus ortus " par " nay de parens nobles, riches et puissans seigneurs du château et mandement ", l'auteur méritait le jugement que portait sur lui Ludwig Konrad Bethmann, éditeur du Chronicon Novaliciense dans les Monumenta Germaniae historica : "Rochex is est qui unum verbum acceptum sufficiat ut amplam inde historiunculam componat ${ }^{17}$." Dom Rochex est tout aussi aventureux sur le terrain de la philologie. "Ambolianensis oppidum » ou "Ambelli castelli» peut difficilement être interprété comme une forme primitive de Lambesc en passant par Lambelli, Lambellées ou Lambées ${ }^{18}$. Le

13. À partir de 1664, les assemblées générales des communautés de Provence se tiennent à Lambesc.

14. Arch. dép. des Bouches-du-Rhône, 129 E GG 7, fol. 3r-3v.

15. Dom J.-L. Rochex, La gloire de l'abbaye et vallée de la Novalese..., p. 90.

16. Ibid., p. 99-100.

17. Chronicon Novaliciense, éd. Ludwig Konrad Bethmann, MGH, SS, t. VII, Hanovre, 1846, p. 75, n. 17.

18. Le testament d'Abbon mentionne parmi des "locella in pago Vuaspacense " le lieu-dit Ambillis, identifié comme Ambel (Isère) par Patrick J. Geary, Aristocracy in Provence: 
toponyme Lambiscum est attesté dès 814 dans le polyptyque de Wadalde et se retrouve régulièrement dans les chartes de l'abbaye Saint-Victor de Marseille ${ }^{19}$. Quant à la Durance, son nom latin, tel que l'écrit Tite-Live, est Druentia et non Dederausum ${ }^{20}$. De surcroît, le village n'est pas vraiment proche de cette rivière, qui ne traverse pas le territoire communal, et, surtout, il n'est pas entouré de toutes parts par les Alpes. La lecture de dom Rochex n'en convainc pas moins le curé Aubert que sa paroisse est le lieu de naissance de saint Eldrad. Il n’en est que plus chagriné par les dernières lignes de la lettre de l'abbé de la Novalaise :

«Il finit sa lettre en lui témoignant le regret qu'il avoit de ne pouvoir lui envoyer des reliques du saint, attendu qu'elles sont enfermées dans une grande châsse d'argent et qu'il n'est permis à personne d'en faire l'ouverture. Son reffus ne fit qu'enflamer davantage son zèle. Et, pour obtenir ces saintes reliques, tout fut mis en usage auprès des personnes qui avoient le plus de crédit à Turin ou à Rome, mais leur protection nous fut infructueuse. Et Dieu ne vouloit se servir que des plus foibles moyens pour seconder nos vœux quand il en seroit tems ${ }^{21}$."

Le récit passe abruptement à ce temps, qu'il qualifie plus loin d' " heureux », sans expliciter ce "faible moyen ». L'auteur de la notice consacrée à saint Eldrad dans le Dictionnaire de la Provence d'Achard, en 1786, écrit que le curé Aubert s'adressa pour parvenir à ses fins à la princesse de Carignan ${ }^{22}$. En effet, si l'on en croit Paul Guérin, une part des ossements de saint Eldrad qui n'avaient pas été enfermés dans la châsse conservée à l'abbaye avaient été distribués à diverses églises de Turin et d'ailleurs ou devinrent propriété de la famille de Savoie. Et d'ajouter que « c'est de la maison des princes de Savoie que M. Aubert, curé de Lambesc, reçut en 1743 le fragment d'os important qui orne l'autel du bienheureux Heldrad dans sa ville natale. La remise de cette relique eut lieu diplomatiquement par l'entremise de l'ambassade de France à Turin ${ }^{23}$. » De là, la relique fut envoyée à $\mathbf{M}^{\mathrm{gr}}$ de Brancas, archevêque d'Aix, qui la fit « enchâsser en bonne et due forme avec son procès-verbal et l'authantique dans une châsse en façon d'ébenne enrichie d'ornemens en argent " et surmontée d'un "buste qui représente saint Eldra en habit de bénédictin » ${ }^{24}$.

The Rhône Basin at the Down of the Carolingian Age, Stuttgart, 1985 (Monographien zur Geschichte der Mittelalter, 31), p. 85.

19. Voir Charles Rostaing, Essai sur la toponymie de la Provence, depuis les origines jusqu'aux invasions barbares, Paris, 1950, p. 190-191.

20. Renata CRotTi PAsi, article «Eldrado, santo », dans Dizionario biografico degli Italiani, t. XLII, Rome, 1993, p. 380-383, commet la même erreur, bien qu'elle indique que l'on ignore "l'esatta ubicazione" de la localité.

21. Arch. dép. des Bouches-du-Rhône, 129 E GG 7, fol. 3v-4r.

22. Article "Eldra, ou Oldra, saint ", dans [Claude-François Achard (dir.)], Dictionnaire de la Provence et du comté Venaissin, t. III, Contenant l'histoire des hommes illustres de la Provence, Marseille, 1786, p. 257-258. Il s'agit de Victoire, bâtarde de Savoie (1690-1766), fille du duc Victor-Amédée-François et de Jeanne d'Albert de Luynes, mariée en 1714 à Victor-Amédée de Savoie, prince de Carignan. Je remercie Frédéric d'Agay, qui m'a fourni cette identification.

23. $\mathrm{M}^{\mathrm{g}}$ Paul Guérin, Les petits Bollandistes : Vies des saints de l'Ancien et du Nouveau Testament, des martyrs, des pères, des auteurs sacrés et ecclésiastiques, des vénérables et autres personnes mortes en odeur de sainteté [...], d'après le père Giry, $7^{\mathrm{e}}$ éd., Paris, 1876, t. III, p. 404.

24. Arch. dép. des Bouches-du-Rhône, 129 E GG 7, fol. 4r. 


\section{L'entrée solennelle}

La relique est accueillie à Lambesc le 13 mars 1743, «jour auquel on en célèbre la feste dans la vallée de la Novalaise », par une véritable entrée solennelle, associant occursus et adventus :

«Une procession des plus solennelles, composée de tous les corps eclésiastiques, religieux et laïques de la ville, lui vint au-devant. La sainte relique fut portée sous le dais par des prêtres habillés en lévites au son des cloches et à la triple descharge des boettes. Rien n'ètoit plus touchant à voir que les exès de joye et la modestie avec laquelle tout le peuple entier de Lambesc accompagnoit la procession, tandis que les ministres du Seigneur chantoient l'himne composée à l'honneur du saint ${ }^{25}$."

La relique est portée sur l'autel richement paré de la chapelle consacrée à saint Eldrad. Une messe solennelle est célébrée, au cours de laquelle le panégyrique du saint est prononcé. Elle s'achève par la bénédiction «donnée avec le très saint sacrement ». Les Lambescains assistent en nombre à la cérémonie, mais aussi des étrangers, "en grand concours » 26.

L'entrée des reliques s'accompagne d'un miracle, opéré sur Marie Garcin, femme du « maréchal à forge » Jacques Fouques :

«Elle étoit détenue dans son lit, attaquée d'un rhumatisme universel depuis longtemps. Sa dévotion la porta à demander avec instance qu'on la transportât de son lit à la rue par où la sainte relique devoit passer. Au moment qu'elle l'apperçut, elle fit sa prière et, au grand étonnement de tous les assistans, elle fut délivrée à l'instant de sa maladie, marcha sans secours, et, rendant grâces au Seigneur, elle s'écria : "Miracle !" La vérité de ce fait a été attesté dans le procès-verbal dressé par ordre de monseigneur l'archevêque ${ }^{27}$."

C'est le début d'une série de prodiges. «Depuis lors, plusieurs personnes ont obtenu du ciel toutte sorte de secours spirituels et temporels lorsqu'elles se sont adressées à saint Eldra avec une foy vive ${ }^{28}$. " Le registre de la confrérie cite le cas du marquis de Vauvenargues, atteint de la petite vérole, qui obtint le rétablissement de sa santé et recouvra la vue à la suite d'un vœu adressé à saint Eldrad par une de ses parentes, religieuse aux ursulines d'Aix, sans doute peu après l'installation du culte du saint à Lambesc. Le 18 mai 1746, un enfant appelé Eldra — on voit que le vocable du saint n'a pas tardé à devenir un nom de baptême - âgé d'environ vingt et un mois, " se laissa tomber sous la roue d'un chariot chargé pour l'armée des Espagnols en Italie ${ }^{29}$. La mère, voyant son enfant dans un danger évident de mort, s"écria : "Ah ! Grand saint Eldra, sauvés mon fils !" À ces mots, par une merveille surprenante, les chevaux s'arrettèrent, et, avec quelques efforts qu'on fit, l'enfant fut tiré de

25. Ibid.

26. Ibid., fol. $4 \mathrm{v}$.

27. Ibid.

28. Ibid.

29. L'événement se situe durant la guerre de Succession d'Autriche. Dans ce conflit, la France est alliée aux Bourbons d'Espagne et de Naples contre l'Autriche et le roi de Sardaigne, de la maison de Savoie. Lambesc est ville d'étape sur le trajet des troupes. Ce chariot fait partie du convoi qui se dirige vers Nice et le Piémont, possessions savoyardes. 
dessous la roue, n'ayant pour tout mal que quelques meurtrissures au bas ventre qui ne l'empêchèrent pas de marcher ${ }^{30}$. » Ses parents, Joseph Jullien et Magdelaine Cartier, font peindre un ex-voto représentant la scène.

Cet ex-voto prend place sur les murs de la chapelle que le curé Aubert a consacrée à ce saint. Elle est également ornée, depuis sa dédicace, d'un grand tableau placé à l'intérieur d'un retable daté de $1742^{31}$, dû au peintre aixois François Dandré-Bardon (1700-1783) et commandé par un certain JeanBaptiste Seguin ${ }^{32}$, qui représente un miracle de saint Eldrad. Au premier plan, un homme à moitié nu représenté de dos tient une torche qui éclaire le suaire déployé et les chairs livides d'un cadavre tout juste exhumé d'un caveau qui revient à la vie par l'intercession du saint. Eldrad, un bénédictin au visage auréolé, lève la main gauche dans un geste d'autorité et s'appuie de la main droite sur une crosse épiscopale. Divers personnages l'entourent, inégalement éclairés, un invalide, une femme et des enfants. À l'arrière-plan se dressent les tours et le rempart d'une ville fortifiée. Ce n'est pas l'illustration exacte d'un prodige opéré par le saint. Un seul miracle de résurrection, en effet, est rapporté dans la Vita Eldradi, et c'est un miracle post mortem. Alors que la foule affluait pour se rendre sur le tombeau d'Eldrad, un pont sur le Pô se rompit sous le poids, les pèlerins tombèrent dans l'eau, et une femme, tout particulièrement désireuse de voir les reliques, "foeminae naturae fragilitate detente, sub vastis aquis spiritum exhalaret ». Ses enfants implorèrent alors saint Eldrad et portèrent le corps de leur mère sous le cercueil dans lequel le saint reposait. Au contact des reliques, la mère ressuscita ${ }^{33}$.

La relique est arrivée à Lambesc « après que la dernière main a été mise à la construction de la magnifique église qui avoit été commencée au même lieu où étoit le château de saint Eldrad " ${ }^{34}$. En décembre 1699, la commune de Lambesc avait décidé de démolir la première église Notre-Dame-de-la-Rose, qui datait de l'époque romane et qui menaçait ruine, et de la remplacer par un édifice de plus grandes dimensions. Le dossier de cette reconstruction, commencée en 1700, a été minutieusement étudié par Jean Boyer à partir des délibérations et des comptes communaux. Il était prévu, écrit-il en reprenant les termes des registres communaux, « de raser les restes de l'ancien château

30. Arch. dép. des Bouches-du-Rhône, 129 E GG 7, fol. 6r.

31. Il est antérieur d'un an à la réception de la relique par le curé Aubert. Le commanditaire a donc eu connaissance, au moins indirectement, du livre de dom Rochex.

32. Le tableau porte l'inscription : «J. B. S. benf.tor». Je n'ai pu identifier précisément ce commanditaire. Un Jean-Baptiste Seguin fait célébrer son mariage à Lambesc en 1693 (Éric Vivian, Table des mariages de Lambesc, 1996, dactyl., p. 74). Je remercie $\mathbf{M}^{\text {me }}$ Ludmila Virassamynaïken, conservateur au musée des beaux-arts de Lyon, qui prépare un catalogue de l'œuvre de François Dandré-Bardon, des informations qu'elle a bien voulu me communiquer.

33. Monumenta Novaliciensia vetustiora : raccolta degli atti e delle cronache riguardanti l'abbazia della Novalesa, éd. Carlo Cipolla, t. I, Rome, 1898 (Fonti per la storia d'Italia, 31. Scrittori. Secoli viII-XI), p. 389-390. Le dépliant édité pour la célébration de la fête de saint Eldrad à Lambesc le 13 mars 2016 indique à tort que le tableau représente le " miracle des serpents ", par lequel Eldrad délivre des serpents qui l'infestaient une localité de la vallée de Briançon (Stabatio, aujourd'hui Le Monêtier-les-Bains) dans laquelle certains des moines de la Novalaise se sont établis sur son ordre.

34. Arch. dép. des Bouches-du-Rhône, 129 E GG 7, fol. 4r. En fait, l'église ne sera terminée qu'en 1757. 
des princes de Lambesc et le rocher sur lequel il était assis afin de construire le reste de l'édifice, c'est-à-dire la nef et les bas-côtés ", de réemployer dans la maçonnerie les pierres de taille provenant du vieux château qui menaçait de s'écrouler et "de faire de poustouire au rocher du vieux chasteau " ${ }^{35}$. Le château avait été donné à la communauté de Lambesc par Louis, comte d'Armagnac, prince de Lorraine, alors seigneur de la localité. Il a appartenu au Moyen Âge à la famille de Lambesc, puis conjointement au comte de Provence et à divers coseigneurs. En 1348, la reine Jeanne a donné la part de la Couronne à Pierre de Lamanon, et, lors de l'enquête de Véran d'Esclapon, en 1379, le fortalicium est aux mains d'Isnard de Pontevès ${ }^{36}$. Au demeurant, il ne s'agit pas du château primitif de Lambesc, détruit de fond en comble par Raimond-Bérenger V en 1222, dont le lieu-dit "le Castellas " conserve le souvenir ${ }^{37}$. Mais, pour le curé Aubert et les membres de la confrérie de saint Eldrad, et, bien vite, pour l'ensemble de la population de Lambesc, il ne peut être que le palais de la famille de saint Eldrad, seigneur de la localité au haut Moyen Âge ${ }^{38}$. Sur le mur de gauche du transept, à l'emplacement d'une ancienne tour d'enceinte sur laquelle a été montée la souche du clocher ${ }^{39}$, au-dessus d'une porte, figure l'inscription « D. O. M. Vetero everso, templum istud in aedibus avitis divi Eldradi, civis Lambescensis, in meliorem formam anno Domini MDCC munificentia publica erectum. Ad rei memoriam parochus aedituique $P$. $P$." ${ }^{40}$.

La porte d'accès au clocher est, aux yeux des Lambescains, l'ancienne porte du château d'Eldrad et de ses parents.

\section{L'invention d'une histoire}

Il restait à inscrire plus profondément le personnage d'Eldrad, sa famille et les débuts de sa vie dans le paysage de Lambesc. Dans le dernier paragraphe

35. J. Boyer, «L’église de Lambesc »..., p. 192 et 202.

36. Thierry PÉcout (dir.), L'enquête générale de Leopardo da Foligno en Provence occidentale (octobre 1331 et septembre-décembre 1333), Paris, 2013 (Coll. de documents inédits sur l'histoire de France. Série in-8 $\left.{ }^{\circ}, 66\right)$, p. 231-232.

37. Joseph-Hyacinthe Albanès, «La chronique de Saint-Victor de Marseille », dans Mélanges d'archéologie et d'histoire, t. 6 (1886), p. 321.

38. Encore aujourd'hui, on peut lire sur le site officiel de la commune de Lambesc que "l'église [...] a été édifiée de 1700 à 1741 à la place du manoir de saint Eldrad (premier seigneur de Lambesc, patron de la cité et des bergers) » (http://www.lambesc.fr/reset/all/34l-place-despoilus-et-eglise-notre-dame-de-l-assomption-classee-monument-historique.htm [site consulté le 16 août 2017]). Toujours sur Internet, sous le titre « Le château de saint Eldrad@ Lambesc », un internaute a publié sur la chaîne Youtube le 5 octobre 2014 une photographie du clocher de l'église avec ce commentaire : "La tour carrée ( $\mathrm{Ix}^{\mathrm{e}}$ siècle) du château de saint Eldrad, surmontée par le clocher de l'ancienne église romane Notre-Dame-de-la-Rose (xıII ${ }^{\mathrm{e}}$ siècle), lui-même intégré à l'église Notre-Dame-de-l'Assomption " (https ://www.youtube.com/watch?v=fA9H7eg7VPw [site consulté le 16 août 2017]).

39. J. Boyer, « L’église de Lambesc »..., p. 192.

40. "À Dieu très bon et très grand. Ce temple, l'ancien ayant été détruit, a été érigé dans le palais ancestral de saint Eldrad, citoyen de Lambesc, et a reçu une plus belle forme grâce à la munificence publique, l'an du Seigneur 1700. En mémoire de quoi, le curé et les ouvriers ont apposé à leurs frais cette inscription. " 
du long récit de son entrée à Lambesc, le registre de la confrérie recense les textes relatifs à la vie du saint auxquels les Provençaux pouvaient alors avoir accès. Il s'agit, tout d'abord, de l'ouvrage de dom Rochex, qui s'est fondé sur un manuscrit liturgique, un office de saint Eldrad connu par une copie du XVII $^{\mathrm{e}}$ siècle contenue dans le tome III du sanctoral de l'abbaye. Sans trop se soucier d'en donner une transcription scrupuleuse ${ }^{41}$, il s'en est servi pour composer le récit continu de la biographie du saint et en a publié une partie sous le titre « Probatio vitae beati Eldradi, monachi et abbatis Novalicii, ex notis ipsius abbatiae » ${ }^{42}$. Le texte qu'il reproduit diffère sur quelques points de celui qui est parvenu jusqu'à nous. En particulier, la localisation du castellum Ambelli, "prope flumen Dederausum ", ne figure pas dans le manuscrit aujourd'hui conservé, mais la présence de cette mention dans une légende des fresques représentant la vie de saint Eldrad sur les murs d'une chapelle de la Novalaise décorée au $\mathrm{xI}^{\mathrm{e}}$ siècle laisse penser qu'elle pouvait figurer dans un autre texte de l'office que dom Rochex aurait pu consulter ${ }^{43}$. Ce membre de phrase est absent également du texte de la Vita soluto sermone scripta, dont on peut dater la rédaction du xiI ${ }^{\mathrm{e}}$ siècle, mais dont on a perdu l'original ou la copie qui s'est trouvée en 1654 entre les mains du père jésuite Giovanni Giacomo Turinetti, qui l'a publiée dans les Acta sanctorum à Anvers en $1668{ }^{44}$. Ce document, qui a servi de base à l'édition de référence de la Vie d'Eldrad donnée par Carlo Cipolla en 1898 45, était connu en Provence dès les premières décennies $\mathrm{du} \mathrm{xIx}^{\mathrm{e}}$ siècle. Le registre mentionne également l'ouvrage, consulté par dom Rochex, de Marco Antonio Carretto, Vita e miracoli di s. Eldrado, abbate dell'insigne monastero di S. Pietro della Novalesa (Turin, 1693), ouvrage peu fiable, le Catalogue des saints d'Italie de Filippo Ferrari ${ }^{46}$ et le « martirologe bénédictin » du "père Busselin » ${ }^{47}$.

Sur l'origine et la jeunesse de saint Eldrad, dom Rochex avait repris l'essentiel de ce qui est dit dans la Vita Eldradi ${ }^{48}$. Né de parents nobles et riches dont on s'est empressé de faire les seigneurs du village d'A mbelliacum/Lambesc, il fait le choix d'une vie pauvre, se revêt d'humbles habits semblables à ceux des paysans ${ }^{49}$, il distribue ses biens aux miséreux et emploie son héritage « à bâtir

41. Monumenta Novaliciensia vetustiora..., t. I, p. 350 : «Come e suo costumo, non e del tutto scrupuloso nella riproduzione del testo. "

42. Dom J.-L. Rochex, La gloire de l'abbaye et vallée de la Novalese..., p. 90-124.

43. Voir Costanza Segre Montel, "Affreschi medievali alla Novalesa e in Valle di Susa: testimonianze di pittura murale tra VII et XII secolo", dans La Novalesa: ricerche, fonti documentarie, restauri, [Novalaise, 1988], t. I, p. 61-181.

44. Vita [sancti Heldradi, abbatis Novalitii], éd. Giovanni Giacomo Turinetri, Acta sanctorum, Martii, t. II, Anvers, 1668, p. 333-338.

45. Monumenta Novaliciensia vetustiora..., t. I, p. 382-398.

46. Filippo FErrari, Catalogus sanctorum Italiae, in menses duodecim distributus [...], Milan, 1613.

47. Il s'agit en fait du Menologium Benedictinum, du père Gabriele Bucelin, publié à Feldkirch en 1655.

48. Sur les manuscrits de ce texte et ses éditions, voir Pio TAMBurino, «Temi agiografici nella Vita Heldradi ", dans Esperienze monastiche nella Val di Susa medievale, éd. Luca Patria et P. Tamburino, Suse, 1989, p. 143-146.

49. Dom J.-L. Rochex, La gloire de l'abbaye et vallée de la Novalese..., p. 92 : « Il [...] se vêtit des habits de pauvres Contadins." 
au lieu de sa naissance [...] une grande et magnifique eglise à l'honneur du prince des apôtres, saint Pierre, [...] et tout auprès de ladite eglise y fit bâtir quantité de cellules pour y loger et recevoir tous indifferemment qui là viendroient en devotion et pour assister à l'office divin ${ }^{50}$.

Après quoi, ayant épuisé ses ressources, il quitte « sa patrie et [le] lieu de sa naissance » vêtu en mendiant et se met en quête d'un monastère dans lequel il trouverait une observance rigoureuse de la vie monastique ${ }^{51}$. Après avoir parcouru la Provence, l'Aquitaine et l'Espagne, il se rend en Italie et se fixe au monastère de la Novalaise.

Il restait à donner plus de consistance à ce récit en l'inscrivant dans le paysage lambescain. En 1786, Claude-François Achard, dans son Dictionnaire de la Provence, y a contribué en évoquant, sans la désigner par son vocable, l'église de Saint-Pierre, dont les ruines subsistent au quartier du même nom. Insistant sur la volonté du saint de se dépouiller de ses biens, il le montre s'employant à "bâtir une église en l'honneur du prince des apôtres, qu'il décora de magnifiques ornemens ». Il ajoute : "Il y fonda plusieurs places de chapelains et fit construire à l'entour quantité de cellules pour recevoir les personnes que la dévotion y attireroit. Il ne reste aujourd'hui que les traces de cette église, que le concours des fidèles avoit rendue fort célèbre ${ }^{52}$. "

Mais cette contextualisation s'affirme surtout dans le tome II de la Statistique du département des Bouches-du-Rhône, publié en 1824, où l'on peut lire deux notices historiques consacrées à Lambesc, vraisemblablement dues à ce même maire Jacques Martin-Jaubert ${ }^{53}$ qui, dans sa réponse à l'enquête du préfet Villeneuve, signalait la célébration de la fête de saint Eldrad, " seigneur et citoyen de Lambesc ». Dans une section intitulée « Géographie ancienne », au chapitre Xv, "Géographie francique », l'auteur note que Lambesc et SaintCannat sont les seules localités de la viguerie d'Aix sur lesquelles existent quelques documents, à savoir, pour Lambesc, la Vie de «saint Eldrad, abbé de Novalèse en Piémont, [...] seigneur d'un pays appelé oppidum Amboliacense, dans l'enceinte duquel il fit bâtir une église en l'honneur de saint Pierre. Les ruines de cette chapelle existent encore au quartier de San-Peyré, terroir de Lambesc, entre cette ville et Rognes. Le mot oppidum [...] indique que c'était un lieu fortifié, et Amboliacense peut être considéré comme l'adjectif d'Ambolium, qui est une altération d'emporium ${ }^{54}$."

50. Ibid., p. 93. La naissance noble et la pauvreté volontaire pour le Christ sont thèmes hagiographiques obligés d'une Vie de saint, comme le souligne P. TAmburino, "Temi agiografici nella Vita Heldradi »..., p. 148-151.

51. Dom J.-L. Rochex, La gloire de l'abbaye et vallée de la Novalese..., p. 94.

52. Article "Eldra, ou Oldra, saint », dans [C.-F. Achard (dir.)], Dictionnaire de la Provence..., p. 258.

53. Ce personnage, dont les descendants subsistent à Lambesc, n'est connu que comme "propriétaire ", mais cette désignation peut s'appliquer à des individus d'un niveau culturel élevé, comme Fernand Cortez, auteur du toujours précieux répertoire des grands officiers du comté de Provence, qui figure au bureau de la Société d'études provençales avec le titre de "propriétaire à Saint-Maximin ».

54. Christophe DE Villeneuve, Statistique du département des Bouches-du-Rhône, t. II, Marseille, 1824, p. 334. 
L'imagination de dom Rochex trouve ici une base philologique. Et le site s'inscrit dans le temps long avec la phrase finale : "Oppidum Amboliacense était donc un ancien marché qu'on avait probablement fortifié au temps des Sarrasins ${ }^{55}$. » Une seconde notice figure dans la partie intitulée « Topographie administrative : administration départementale et statistiques départementales ». Le rédacteur propose une explication logique à l'existence de l'emporium en la rattachant à l'histoire antique de la Provence :

«Les Grecs de Marseille avaient établi un marché entre Rognes et Lambesc où ils se rendaient à certaines époques de l'année pour y trafiquer ${ }^{56}$. Peu à peu, il se forma dans le lieu où était ce marché un bourg qui est nommé Oppidum Amboliacense dans le $8^{\mathrm{e}}$ siècle, c'est-à-dire "Bourg du marché". Saint Eldrad, qui en était seigneur et qui mourut abbé de Novalèse en Piémont, y fit bâtir une église en l'honneur de saint Pierre ; c'est celle qui se voit encore au quartier de San-Peyré, auquel il a donné son nom [...].

"Il paraît qu'à cette époque la population était encore réunie à Saint-Pierre, et que du mot Amboliacense on fit Lamboliacum, Lamblicum et Lambiscum ${ }^{57}$."

L'église Saint-Pierre, dont quelques ruines subsistent, est une construction de l'âge roman et ne peut être celle qu'Eldrad aurait fait construire. La situation du quartier de San-Peyre, à l'extrémité est du territoire communal, rend difficile l'identification entre le site d'Amboliacum et l'emplacement présumé du château de la famille d'Eldrad, à côté de l'église Notre-Dame-dela-Rose. En 1835, le Dictionnaire historique et topographique de la Provence ancienne et moderne, de Garcin, reprend les mêmes données ${ }^{58}$.

Le texte de la Statistique est ensuite repris dans un Recueil de prières propres aux principales fêtes et aux divers temps de l'année selon l'esprit de l'Église publié à Aix en 1837, qui contient une Vie de saint Eldrad ainsi qu'un cantique en son honneur ${ }^{59}$. L'auteur, «Jean-Joseph Isoard de Lambesc, maître de pension à Nice » ${ }^{60}$, précise que « la vie ici rapportée est extraite des Bollandistes, écrite en latin par P. Turinetto [sic], recteur du collège de Turin, le P. Rocher [sic] la donna en français et dom Carette en italien » ${ }^{61}$. Il ajoute

\section{Ibid.}

56. La Carte archéologique de la Gaule n'a relevé dans ce terroir aucun emporium que l'on puisse rattacher aux Massaliotes. En revanche, une forte occupation antique y est attestée, avec notamment deux oppida à Sainte-Anne-de-Goiron et à Suès et de nombreux établissements agricoles de la période romaine, époque ignorée par la Statistique (Carte archéologique de la Gaule, $\mathrm{n}^{\circ}$ 13/4, Aix-en-Provence, pays d'Aix et val de Durance, dir. Florence Mocai et Núria Nin, Paris, 2006, p. 582-586).

57. C. de Villeneuve, Statistique du département des Bouches-du-Rhône..., t. II, p. 939.

58. Étienne Garain, Dictionnaire historique et topographique de la Provence ancienne et moderne, Draguignan, 1865, vol. II, p. 23.

59. [Jean-Joseph IsOARD], Recueil de prières propres aux principales fêtes et aux divers temps de l'année selon l'esprit de l'Église, suivi de la Vie de saint Eldrad, d'une méditation sur les vertus fondamentales de la vie chrétienne, et de quelques autres prières, Aix, 1837. Cette brochure a été publiée à nouveau à Turin, par les soins des religieux bénédictins de la Novalaise, en 1851 (un exemplaire en est conservé au musée Paul-Arbaud d'Aix-en-Provence dans le carton 313), puis réimprimée à Aix-en-Provence en 1857.

60. C'est ce qu'indique une mention figurant au crayon dans l'exemplaire conservé à la bibliothèque Méjanes à Aix-en-Provence sous la cote In-8 pes 01673. Il s'agit vraisemblablement de Joseph Isoard, l'acolyte qui compile en 1814 le coutumier liturgique de la paroisse de Lambesc (voir la n. 89 ci-dessous).

61. [J.-J. IsOARD], Recueil de prières propres aux principales fêtes..., p. 30. 
que les restes de l'église Saint-Pierre bâtie par Eldrad sont encore visibles, qu'elles indiquent un édifice $\mathrm{du} \mathrm{rx}^{\mathrm{e}}$ siècle, et que l'on y a découvert des tombeaux et beaucoup d'ossements humains.

Avec cet ouvrage, la vulgate de l'histoire de saint Eldrad est établie pour un siècle. On la retrouve inchangée, un quart de siècle plus tard, sous la plume de l'abbé Constantin, dans son recueil de notices historiques sur les paroisses du diocèse d'Aix, qui y ajoute une confusion regrettable entre la chapelle Saint-Pierre de Lambesc et l'église Saint-Pierre « al culhidor ", dans le terroir de Saint-Canadet ${ }^{62}$.

Ce récit est enrichi de nouveaux détails qui comblent le vide entre l'oppidum/marché et la seigneurie de la famille d'Eldrad dans la brochure d'Alphonsine Saint-Denis, Lambesc à travers les âges :

"Jadis, ce territoire était occupé par les Salyens, qui entretenaient des relations commerciales avec les Phocéeens. Ses habitants, éparpillés dans des lieux appelés Suë [= Suès], Taillades, Gouiron, La Baume, etc., se rendaient à des époques déterminées au bourg Oppidum Amboliacense [à deux kilomètres de Lambesc], marché assez important où les Phocéens venaient acheter pour leurs navires la résine et le goudron apportés là par les peuplades des environs. Ce marché et ses environs furent saccagés alternativement en 575 et 580 par les Lombards et les Saxons. Les quelques habitants échappés aux massacres se réfugièrent avec leur chef Heldrad dans un bois fourré appelé Lambiscum, Lambesc aujourd'hui. Quelques petites maisons, entourées de palissades y furent édifiées, et leur chef Heldrad devint leur seigneur. En 732, après la célèbre bataille de Poitiers remportée sur les Sarrasins par Charles Martel, les débris de l'armée vaincue se répandirent dans le Midi de la France, et quelques détachements de ces hordes sauvages dressèrent leurs tentes à Lambesc dans le quartier appelé encore aujourd'hui Plan Bédouin. C'est de là qu'ils partaient pour faire des razzias dans les environs et, chargés de butin, ils rentraient dans leur camp en dansant au son de leurs bruyants instruments. La farandole que de nos jours les jeunes conscrits exécutent à l'époque du tirage au sort au son des fifres et des tambours est sans doute une réminiscence de la danse et musique des Sarrasins perfectionnée par l'art provençal [...] 63. En 734, Charles Martel chassa les Sarrasins de la Provence et conféra le gouvernement de cette province à son lieutenant Boson et maintint Heldrad dans sa seigneurie de Lambesc. À la mort de ses parents, Heldrad, leur descendant, naquit à Lambesc en 781, hérita de tous leurs biens, les vendit et en distribua l'argent aux pauvres. Il se rendit en Piémont [...] ${ }^{64}$."

Il restait encore des zones d'ombre dans la période provençale de la vie d'Eldrad. Elles seront comblées au début du $\mathrm{xx}^{\mathrm{e}}$ siècle. L'acteur principal de cet enrichissement est un habitant de Lambesc, Émile Turc, entré comme convers à l'abbaye de Hautecombe, où il prit le nom de frère Eldrad ${ }^{65}$.

62. Abbé Marie-Siméon Constantin, Les paroisses du diocèse d'Aix, leurs souvenirs et leurs monuments, t. I, Paroisses de l'ancien diocèse d'Aix, Aix-en-Provence, 1890 (La sainte Église d'Aix et Arles, 7), p. 524-532.

63. Suit, annoncée par «En voici l'air », la notation musicale d'une mélodie.

64. Alphonsine SAINT-Denis, Lambesc à travers les âges, Marseille, 1910, p. 6-7. Cette mince brochure a obtenu le « diplôme d'honneur » au grand concours littéraire de "La Vieille France " à Paris en 1908 sous la présidence d'honneur de Frédéric Mistral et de Alfred Mezières, François Coppée, René Bazin et Maurice Barrès.

65. Né le 12 août 1858 à Lambesc, il fit profession à l'abbaye Sainte-Marie-Madeleine de Marseille et mourut à Hautecombe le 22 février 1929 (L'abbaye de Sainte-Madeleine de Marseille (1865-2015), s. 1., 2015, p. 95). 
Il fournit en 1923 à l'abbé Auguste Pascal, curé du Monêtier-les-Bains, la matière d'une brochure intitulée Saint Eldrade et le Monêtier-les-Bains, parue anonymement à Gap en 1924 66. Dans cet opuscule, les membres de la famille de saint Eldrad sortent de l'anonymat :

"C'était vers la fin du virI e siècle, en l'an 781. Le château d'Ambolia (aujourd'hui Lambesc, dans les Bouches-du-Rhône) était en fête. Un enfant venait d'être donné à Leodda, épouse du seigneur Ardradus, capitaine burgonde dont l'ancêtre s'était fixé dans le pays ${ }^{67}$."

L'auteur se hasarde à quelques hypothèses sur la jeunesse d'Eldrad : « Si ses parents lui ont enseigné les rudiments, on ignore quelle école eut l'honneur de le recevoir, mais il est à croire qu'il prit le chemin de l'école claustrale ou de la palatine ${ }^{68}$. » Devenu orphelin en 810, il fait « le choix de l'humilité et de la pauvreté ». Il renonce " aux insignes de sa dignité [et] dépose son épée au pied du crucifix [...]. Il réforme sa maison seigneuriale en réduisant tout à la simplicité. Les pauvres profitent de ses épargnes. » Il parcourt en prêchant les bourgs et les campagnes et, aux portes de l'oppidum d'Amboliacum, il renverse les temples des idoles et fait élever à leur place une basilique en l'honneur de saint Pierre, à laquelle il annexe un hôpital. Il se dépouille progressivement de tous ses biens, et une note relève « un fait qui nous montre la générosité d'Eldrad : il fait à l'église de Marseille don de 22 colonies " ${ }^{69}$. Ainsi Eldrad devient-il l'ancien propriétaire des terres recensées dans le polyptyque de Vuadalde !

D'autres « érudits » lambescains vont enrichir cette histoire en puisant le plus souvent dans les notes accumulées par le frère Eldrad Turc. Ce dernier avait donné un nom au père et à la mère d'Eldrad : Ardrad et Leodda. Le chanoine Firmin Ollivier, dans les années 1930 70, puis, plus près de nous, Marcel Gazanhes (1910-1999) remontent la généalogie du saint. À la tête de cette lignée se situe Bizarde, ou Bizardon, un capitaine burgonde qui combattit aux côtés de Charles Martel en 739 lorsque Mauronte, duc ou patrice de Provence, prit la tête d'une rébellion contre lui. Il fut récompensé par l'attribution de terres confisquées à Mauronte, sur lesquelles il fit construire le château où

66. [Abbé Auguste PAscal], Saint Eldrade et le Monêtier-les-Bains, Gap, 1924. Une lettre du frère archiviste de l'abbaye de Ganagobie (où les moines de Hautecombe se sont récemment transférés) adressée au docteur Gérard Cardin, qui a eu l'obligeance de me la communiquer, justifie l'attribution du texte au frère Eldrad Turc. La correspondance de ce religieux, conservée à l'abbaye de Ganagobie, contient en effet une lettre du 25 septembre 1923 dans laquelle l'abbé Pascal accuse réception du manuscrit du frère. Et le même fonds contient une lettre de l'évêque de Gap félicitant le prêtre de cette édition «d'après les notes et les données du frère Heldrade Turc ». Je remercie le frère archiviste de Ganagobie de m'avoir ouvert le fonds constitué par les nombreux dossiers rassemblés par le frère Eldrad.

67. [Abbé A. Pascal], Saint Eldrade et le Monêtier-les-Bains..., p. 1.

68. Ibid., p. 4.

69. Ibid., p. 14.

70. Chan. F. Ollivier, 781-875, saint Heldrad, citoyen de Lambesc, civis Lambescensis, Marseille, 1929 (le titre reprend la formulation du maire de Lambesc dans sa réponse à l'enquête du préfet Villeneuve, un siècle plus tôt), et ID., Histoire de mon pays, Lambesc... L'abbé Ollivier (1848-1932) était un prêtre du diocèse d'Aix. 
devait naître Eldrad ${ }^{71}$. Quant à Leodda, Marcel Gazanhes en fait une « CeltoLigure ». L'origine de cette reconstitution généalogique doit être cherchée dans une table d'autel paléochrétienne, sans doute $d u v^{e}$ siècle, trouvée à Auriol après la démolition de l'église Saint-Pierre en 1851 et qui fut acquise par un antiquaire de cette localité. C'est là que l'abbé Bargès la vit, et il en donna une description en $1861{ }^{72}$. Sur la surface de cette table figurent deux séries de graffiti nominaux, aujourd'hui presque entièrement effacés et quasiment illisibles. La seconde série, écrite perpendiculairement à la première, comporte six noms : Rege Karolo, Bysarda, Ardradus, Leodda, Eldradus et Adalsinda. Ce serait la trace d'un pèlerinage effectué par la famille d'Eldrad au grand complet ${ }^{73}$. Cette reconstitution se heurte à une sérieuse difficulté, car le premier nom, "Karolo rege», est, selon la récente étude de Yumi Narasawa, identifiable à un fils de Lothaire $I^{\mathrm{er}}$, Charles, roi de Provence entre 855 et $869^{74}$, des dates peu compatibles avec celles que l'historiographie locale retient pour la jeunesse d'Eldrad, né en 781, et avec le personnage historique de l'abbé qui dirigea la Novalaise dans la première moitié du $\mathrm{IX}^{\mathrm{e}}$ siècle. L'affabulation généalogique a été ensuite affinée par l'auteur anonyme d'une «Chronologie des princes, ducs et seigneurs de Lambesc » parue dans le Bulletin des Amis du Vieux Lambesc en 1964. On peut y lire en effet :

"Première période. Les Burgondes (viII ${ }^{\mathrm{e}}, \mathrm{Ix}^{\mathrm{e}}$ et $\mathrm{x}^{\mathrm{e}}$ siècle). Les Burgondes appartenaient à la famille heldradéenne. 740, comte Byssarda. Ce capitaine burgonde succède à ses pères probablement vers 740. Nous lui devons la construction du manoir dont nous retrouvons la forme dans l'église paroissiale actuelle ${ }^{75}$. "

Cette proposition "archéologique» va plus loin que la tradition qui se bornait à affirmer une continuité de l'emplacement. Suit :

«781, comte Ardrad [...]. Il abandonne la seigneurie en 812 au profit de son fils Heldrad et meurt en 875 .

«812, comte Heldrad. Il s'agit de saint Heldrad [...]. Son successeur nous est inconnu, et il est difficile de suivre, d'après les archives en notre possession, la lignée de la famille ${ }^{76}$.»

L'auteur se garde bien d'indiquer la nature et l'origine de ces archives...

L'article que Auguste Dumas consacre à saint Eldrad dans le tome XV du Dictionnaire d'histoire et de géographie ecclésiastiques, paru en 1960, ne

71. Marcel Gazanhes, "Généalogie de saint Eldrad", dans Pampres et lys : organe des méridionaux d'Action française, $\mathrm{n}^{\circ} 75$ (1984), p. 9.

72. Abbé Jean-Joseph-Léandre BARGÈs, Notice sur un autel chrétien antique orné de basreliefs et d'inscriptions latines, découvert dans les environs de la ville d'Auriol (Bouches-duRhône), Paris, 1861. Acquise par un académicien marseillais, ce dernier la donna au musée Granet d'Aix-en-Provence, où elle est conservée dans les réserves, fermées au public.

73. Chan. F. Ollivier, 781-875, saint Heldrad, citoyen de Lambesc..., p. 17. On ne sait pourquoi Adalsinda n'a pas été intégrée à cette généalogie !

74. Yumi Narasawa, Les autels chrétiens du Sud de la Gaule ( $V^{e}-X I I^{e}$ siècles), Turnhout, 2015 (Bibl. de l'Antiquité tardive, 27), p. 64-66. Je dois cette référence à Marc Hiejmans. Cette inscription ne peut donc "être considérée comme l'élément probant qui nous manquait ", comme le croit Alix Bas, dernier défenseur de la tradition (Alix BAs, Eldrad, un saint lambescain : recherches, hypothèses et documents, L'Isle-sur-la-Sorgue, 2008, p. 23).

75. Élie Roussier, "Chronologie des princes, ducs et seigneurs de Lambesc", dans Bulletin des Amis du Vieux Lambesc, $\mathrm{n}^{\circ} 22$ (1964), p. 11.

76. Ibid. 
retient pas toutes ces affabulations, mais il conserve la date de naissance en 781 et l'origine lambescaine du personnage, conférant ainsi à cette tradition locale la sanction de l'histoire savante ${ }^{77}$.

\section{Le culte}

Il est malaisé de suivre l'histoire du culte de saint Eldrad après son entrée triomphale dans Lambesc. Les registres de visites pastorales de la période postrévolutionnaire sont très décevants. Les curés doyens chargés de l'enquête ne sortent pas du cadre d'un questionnaire préétabli et immuable qui ne s'intéresse ni aux autels ni aux fêtes. Le registre de la confrérie de saint Eldrad s'interrompt en 1794 et ne comporte pas de liste des membres. L'attribution du prénom Eldrad, sous la forme Eldra, qui apparaît, comme on l'a vu, dans les années qui suivent l'installation du saint, semble rare par la suite. Un dépouillement des actes de mariages célébrés à Lambesc entre 1600 et 1789 ne recense, sur un peu plus de mille unions, que deux époux portant ce prénom comme prénom usuel, l'un en 1769, l'autre en 1773. Sept des mariés ont comme second prénom Eldra, mais la mention d'un second prénom est loin d'être systématique dans ce relevé ${ }^{78}$. Une liste des élèves de l'école congréganiste de Lambesc dressée en 1878, conservée aux archives diocésaines d'Aix, recense quatre-vingt-trois enfants, dont aucun ne se prénomme Eldrad, ce qui illustre les propos du chanoine Ollivier commentant une lettre du marquis de Jessé-Charleval : "Nous avons connu bien des personnes appelées Heldrad ou Heldradine. Il y en a encore, mais leur nombre va en diminuant ${ }^{79}$."

77. Auguste Dumas, article "Eldrad ", dans Dictionnaire d'histoire et de géographie ecclésiastiques, t. XV, Paris, 1963, col. 129. Auguste Dumas (1881-1968), chartiste, professeur d'histoire du droit à la faculté d'Aix de 1910 à 1950, un des auteurs du tome VII de l'Histoire de l’Église dirigée par Augustin Fliche et Victor Martin, paru en 1943, était pourtant, aux yeux de Paul Ourliac, qui rédigea sa notice nécrologique dans la Bibliothèque de l'École des chartes, un "critique né " (Paul Ourlac, "Auguste Dumas", dans Bibliothèque de l’École des chartes, t. 126 (1968), p. 562). Dumas invite le lecteur dans la bibliographie de l'article à ne pas lire dom Rochex sans tenir compte des réserves exprimées par Bethmann dans son édition pour les $M G H$ du Chronicon Novaliciense (voir la n. 17 ci-dessus), mais il ne se laisse pas moins abuser par les idées reçues en Provence. C'est cette notice en particulier qui est visée par Paul Amargier lorsqu'il écrit qu'il est «curieux de voir ce Provençal indiscutablement alpin annexé de façon péremptoire à la basse Provence par les récentes notices encyclopédiques qui le font naître à Lambesc " (Paul Amargier, "La Provence au miroir des Monumenta de la Novalaise », dans Provence historique, t. 27 (1977), p. 252).

78. É. Vivian, Table des mariages de Lambesc..., p. 30, 48, 50, 51, 52, 66, 75. À Valensole, de la même manière, l'usage des prénoms Maïeul et Mayoline, hommage au grand saint de la localité, est attestée du Moyen Âge à nos jours, mais, dans les listes de feux du xv ${ }^{\mathrm{e}}$ siècle, on ne trouve qu'un très petit nombre d'individus portant ce nom de baptême (voir Noël Coulet, "Les noms de baptême en Provence au bas Moyen Âge : complément d'enquête ", dans Provence historique, t. 56 (2003), p. 187). Mitre à Aix n'est pas mieux servi, comme, d'une manière générale, les saints locaux (voir id., "Un saint local : saint Mitre d'Aix, ses Vies, son culte », dans Provence historique, t. 63 (2013), p. 299-330, et ID., "Les saints locaux dans l'onomastique provençale », dans Le peuple des saints : croyances et dévotions en Provence et comtat Venaissin à la fin du Moyen Âge (actes de la table ronde organisée par l'Institut de recherches et d'études sur le bas Moyen Age avignonnais du 5 au 7 octobre 1984), Avignon, 1987 (Mémoires de l'Académie de Vaucluse, 6), p. 167-178).

79. Chan. F. Ollivier, 781-875, saint Heldrad, citoyen de Lambesc..., p. 17. 
Trois ex-voto rendant grâce à saint Eldrad pour son intercession efficace subsistent. Le plus ancien, daté de 1746, représente le sauvetage de l'enfant menacé d'être écrasé sous un chariot (fig. 1) ; un autre, daté de l'an IX de la République (1800-1801), montre saint Eldrad apparaissant à une femme âgée assise sur une chaise à côté d'un lit et illustre sans doute une guérison ${ }^{80}$; le troisième, daté de 1831, représente un père agenouillé devant le lit de son enfant certainement guéri par l'intervention du saint, toujours figuré en bénédictin tenant une crosse ${ }^{81}$. Il est loin d'être certain que tous les ex-voto nous soient parvenus. Mais cette petite collection montre que la confiance à saint Eldrad s'est maintenue jusque dans la première moitié du xix ${ }^{\mathrm{e}}$ siècle. Outre ces trois tableaux votifs, une peinture, conservée actuellement dans la sacristie, représente le miracle des serpents (fig. 2). Sur fond d'un décor forestier arcadien, le saint y est coiffé d'une mitre et tient une crosse, entouré à sa droite de quatre bénédictins et à sa gauche d'un ange fort gracieux, encore qu'un peu raide, tandis que dans la partie droite du tableau trois moines s'activent à poser sous ses yeux les fondations d'un bâtiment. À ses pieds, les serpents qui infestaient le site, de facture assez maladroite, se précipitent dans une crevasse ouverte. Cette toile non datée, sans doute du début du XIx siècle, est signée «L. Mille ». Ce peintre, qui n'a pu être identifié, pourrait, d'après son nom, être d'origine aixoise. Deux cantiques à saint Eldrad ont par ailleurs été publiés avec l'imprimatur des autorités diocésaines. Ils associent le saint et sa «patrie», comme, en 1837 :

Mais, ô Lambesc, d'Eldrad la modestie

Vient te ravir l'objet de ton bonheur ${ }^{82}$.

Deux personnes qui ont vécu l'une et l'autre au $\mathrm{xIx}^{\mathrm{e}}$ siècle se distinguent par l'intensité de leur dévotion au saint.

Alphonse-Antoine-Victor-Louis de Jessé (1809-1900), qui porte le titre de marquis de Charleval par adoption de son oncle Alphonse de Cadenet ${ }^{83}$, est présenté par le chanoine Ollivier comme un "modèle de dévotion à saint Heldrad, citoyen de Lambesc " ${ }^{84}$, dans une brochure de 1929 dédiée à celui qui «d'une manière indéfectible se montra jusqu'à ses derniers jours le propagateur ardent du culte de notre saint patron " ${ }^{85}$. Il envoyait chaque année « son offrande pour l'autel du saint à Lambesc avec un petit bouquet

80. Ex-voto du pays d'Aix [expos. Aix-en-Provence, musée du Vieil Aix, 8 juil.-31 oct. 2008], Aix-en-Provence, 2008, $\mathrm{n}^{\circ}$ 47, p. 30.

81. Seuls les ex-voto de 1746 et de l'an IX sont signalés en ligne, respectivement sous les références PM13002114 et PM13002115, dans la base Mobilier-Palissy du ministère de la Culture, qui recense le patrimoine mobilier français (objets signalés par l'Inventaire général du patrimoine culturel ou protégés au titre des Monuments historiques), à l'adresse : http://www.culture.gouv. fr/culture/inventai/patrimoine [site consulté le 24 août 2017]. Ils ont été inscrits au titre des Monuments historiques le 27 janvier 1975.

82. [J.-J. IsOARD], Recueil de prières propres aux principales fêtes..., p. 48. Une note indique que ce cantique est un "hommage offert à la mémoire de saint Eldrad par Jean-Joseph Isoard ».

83. Le fils de ce dernier, Antoine de Jessé-Charleval, sera maire de Marseille en 1877. Je remercie Frédéric d'Agay des informations qu'il a bien voulu me communiquer.

84. Chan. F. Ollivier, 781-875, saint Heldrad, citoyen de Lambesc..., p. de garde et p. 30.

85. Ibid., p. 6. 


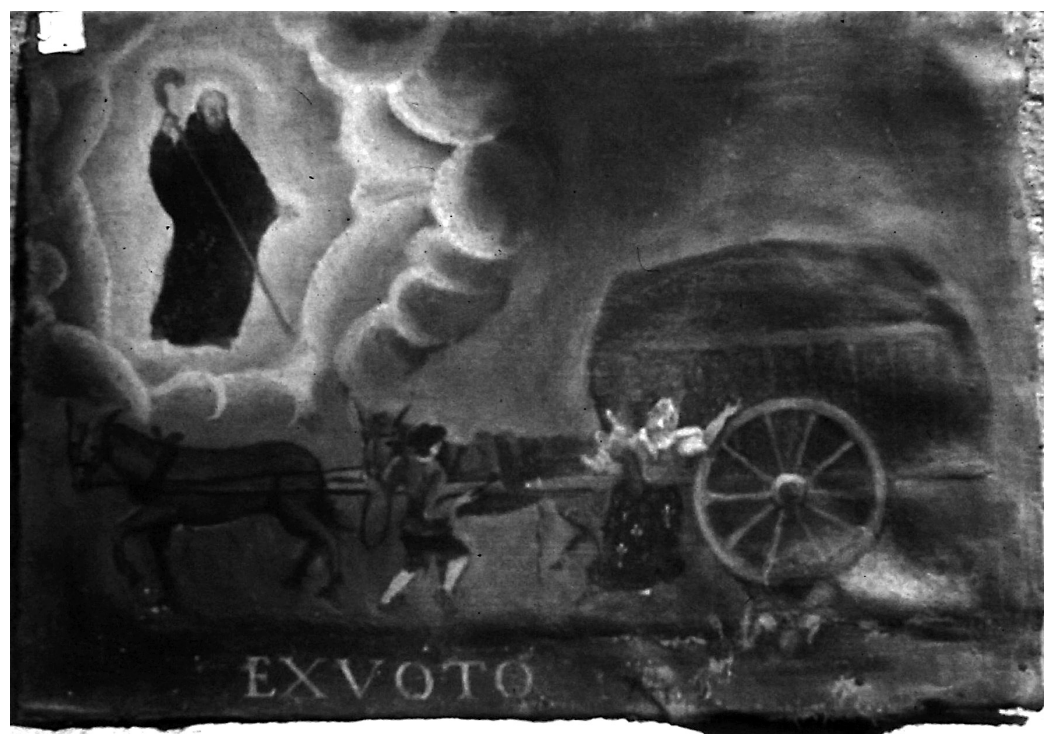

Fig. 1. - Église de Lambesc, ex-voto de 1746 représentant le sauvetage d'un enfant menacé d'être écrasé sous un chariot. Cliché Bernard Cousin.

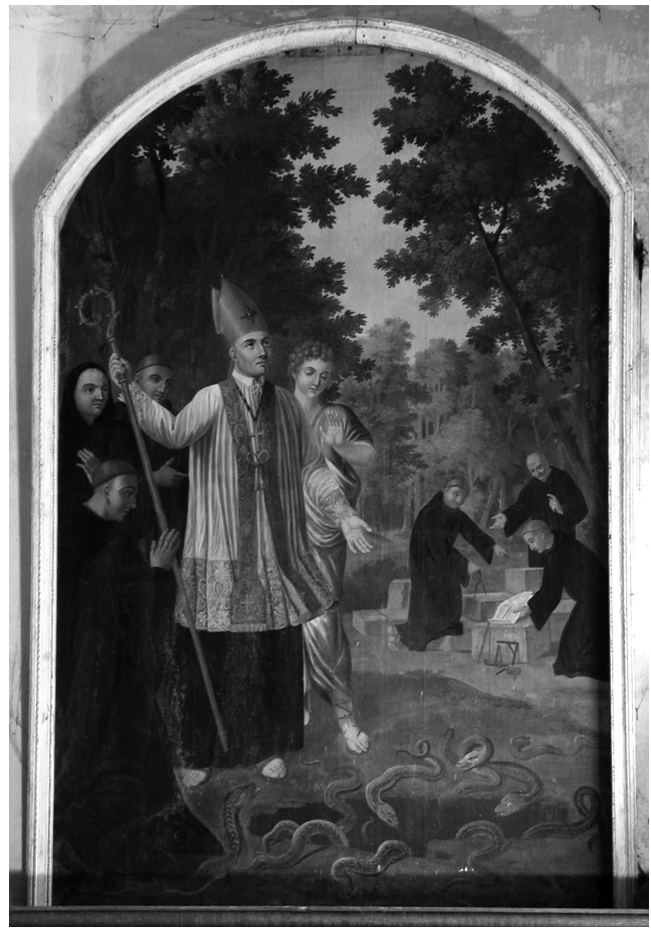

FIG. 2. - Église de Lambesc, sacristie, Le miacle des serpents (peinture sur toile signée «L. Mille », non datée). Cliché Archives diocésaines d'Aix et Arles/Joseph Weisse. 
de fleurs qui devait lui être retourné après avoir parfumé les pieds du saint ce jour-là ainsi que le pain bénit le même jour » ${ }^{86}$. Dans une des lettres qu'il adressait à la sacristine de l'autel du saint pour accompagner son obole, il exprimait l'espoir que des offrandes permettent de racheter un jour la chapelle de San-Peyre et de la faire réparer ${ }^{87}$. Dans une autre lettre du 27 février 1880, il exprime le vœu «que les soldats de Lambesc, qui peuvent être, d'un moment à l'autre, engagés dans une guerre avec l'Italie, épargnent le village de la Novalèse "s'ils venaient à se trouver sur ce front ${ }^{88}$.

Autre dévot inconditionnel du saint, le frère Eldrad de l'abbaye de Hautecombe était l'un des correspondants du marquis, et, pour répondre à un vœu exprimé dans une de ses lettres, il offrit à l'église de Lambesc une photographie de la châsse conservée dans l'église paroissiale de la Novalaise pour qu'elle fût suspendue au-dessus de l'autel.

Un coutumier liturgique de la paroisse de Lambesc, daté de 1814, indique que la fête de saint Eldrad, "natif de Lambesc », est célébrée dans la paroisse le 13 mars ${ }^{89}$. La veille, après complies, un prêtre en soutane se rend à la chapelle du saint pour chanter les litanies propres à ce saint ${ }^{90}$; le lendemain une grand-messe est célébrée le matin à la chapelle d'Eldrad, et le soir on reprend les complies et la litanie de la veille suivies d'une bénédiction du saint sacrement. Il n'y a pas de procession (le coutumier donne la liste de celles qui se déroulent dans l'année ${ }^{91}$ ), et on ne sait quand elle a été introduite dans la fête. Ce n'est sans doute pas avant 1875, date à laquelle Pie IX officialisa et autorisa la célébration de cette fête dans l'église et le diocèse d'Aix. Cette consécration pontificale intervint à la suite d'un échange de lettres entre le curé de Lambesc et $\mathrm{M}^{\text {gr }}$ Forcade, archevêque d'Aix et Arles (1873-1885). Les archives diocésaines conservent quelques fragments de cette correspondance ${ }^{92}$. On y perçoit l'attitude prudente du prélat, qui se manifeste par l'envoi (non daté) des «conditions requises pour que l'on puisse obtenir de Rome la permission de réciter l'office et de faire la fête d'un saint non canonisé ». Le 4 décembre 1874, le curé de Lambesc doit reconnaître qu'il n'a pas «trouvé chez les pères bénédictins de Marseille l'office de saint Eldrad comme on [le lui] avait fait espérer ». Ces religieux lui ont bien « montré, dans les Bollandistes, la Vie du saint ", mais il n'a pas eu le temps de la lire et il espère que « la notice de M. le marquis de Jessé-Charleval, [qui] contient,

86. Ibid., p. 11.

87. Ibid., p. 14 (lettre du 18 mars 1881) et 18 (lettre du 2 mars 1883).

88. Ibid., p. 20. Le marquis fait allusion ici à la tension croissante entre la France et l'Italie, qui culminera en 1881. À l'origine de cette crise des relations entre les deux pays, les visées de la France sur la Tunisie, et sans doute aussi la crainte de voir un régime républicain mettre en péril le statut du Vatican. Je remercie Jean-Marie Guillon, qui m’a aidé à comprendre ce passage.

89. Une copie de ce manuscrit figure dans le dossier "Lambesc » des archives diocésaines d'Aix et Arles. Une photocopie en est conservée à la médiathèque de la Maison méditerranéennes des sciences de l'homme à Aix-en-Provence sous la cote C 1321 a, p. 5.

90. Elles sont publiées dans [J.-J. IsOARD], Recueil de prières propres aux principales fêtes..., p. 38-39, et comprennent un verset «Sancto Eldrade, Lambesci advocate potissime, ora pro nobis".

91. Archives diocésaines d'Aix et Arles, dossier «Lambesc », coutumier liturgique, p. 24-25.

92. Archives diocésaines d'Aix et Arles, dossier "Lambesc ». 
je crois, ce qu'il y a de plus intéressant et plus sûr ", pourra suffire à étayer la demande de la paroisse de Lambesc. Le 29 décembre, il annonce qu'il va écrire à ce même marquis « pour savoir s'il y aurait dans les papiers de Lambesc que l'on avait envoyé à la préfecture il y a bien des années quelque chose qui se rapporte à saint Eldrad " ${ }^{93}$. En attendant, il joint quelques notes prises sur la vie du saint écrite par $\mathrm{M}$. Isoard ${ }^{94}$. Le 12 janvier 1875, il adresse à $\mathrm{M}^{\mathrm{gr}}$ Forcade un "précieux envoi » de "pièces authentiques », accompagné d'une lettre du marquis de Jessé-Charleval où l'on trouve copie de la lettre de dom Rochex à M. de Grignan. La correspondance s'achève, le 3 mars 1875, avec la notification de la réception " avec une douce satisfaction » des indults de Pie IX qui vont permettre de solenniser le 13 le dies natalis de saint Eldrad et de l'inscrire au nombre des saints fêtés dans le diocèse.

La dévotion a connu par la suite une période de fléchissement, dont se fait l'écho Louis Blin, en 1971, dans un article du Bulletin des Amis du Vieux Lambesc : "On célébrait avec un éclat particulier la fête de saint Eldrad, patron de Lambesc, maintenant oublié ${ }^{95}$. " Mais la ferveur est revenue quelques années plus tard, comme en témoigne un poème de quatre strophes " pour la fête de saint Eldrad » publié dans le même bulletin en 1990, dont la première donne le ton :

\footnotetext{
Citoyen de Lambesc, seigneur de ce lieu,

Illustre saint Eldrad, toi qui fais notre gloire,

Lors des ides de mars ravivant ta mémoire,

Nous venons te fêter dans la maison de Dieu ${ }^{96}$.
}

Il s'agit bien d'une forme moderne de religion civique.

Le poème de 1990 ne traduit sans doute qu'une reprise éphémère. Une lettre de l'abbé Jean-Luc Michel, actuel curé d'une paroisse qui désormais regroupe celles de Lambesc, Rognes et Saint-Cannat, indique que « la fête a été remise à l'honneur à l'aube du $3^{\mathrm{e}}$ millénaire, à l'initiative de M. Gazanhes, qui avait connaissance de cette fête au $\operatorname{xIx}^{\mathrm{e}}$ siècle ", et que, nommé à la tête de cette paroisse en septembre 2001, il a «immédiatement accueilli avec enthousiasme cette idée en lui donnant le caractère religieux qui revenait au saint patron de Lambesc " ${ }^{97}$. La fête patronale, célébrée le dimanche le plus proche du 13 mars, comprend une procession à travers les rues du village suivant la bannière et la statue du saint juché sur la châsse qui contient la relique reçue en 1743 (fig. 3), la célébration d'une "belle messe festive » célébrée sur le parvis de l'église paroissiale, et une bénédiction donnée aux animaux et à leurs propriétaires au pied du parvis. L'abbé Michel la décrit en ces termes : «En premier passent les chevaux de trait de M. Blin, suivis de

93. Il s'agit certainement de la documentation mise en œuvre dans la Statistique du préfet Villeneuve.

94. Voir les n. 59 et 60 ci-dessus.

95. Louis Blin, "Vieilles coutumes lambescaines ", dans Bulletin des Amis du Vieux Lambesc, $\mathrm{n}^{\circ} 29$ (1971), p. 14.

96. "Pour la fête de saint Eldrad (le 13 mars), moine bénédictin, natif de Lambesc (781-875) ", ibid., $\mathrm{n}^{\circ} 48$ (1990), p. 28. On retrouve ici une occurrence de la formulation du maire de Lambesc Jacques Martin-Jaubert en 1825.

97. Lettre de l'abbé Jean-Luc Michel à l'auteur, $1^{\mathrm{er}}$ mars 2017. 
bestiaux plus petits (ânes, moutons et chèvres), puis la population avec ses animaux de compagnie ${ }^{98}$. "Suivent des danses folkloriques exécutées par la société Lou Galoubet (fig. 4), qui intervient aussi par des chants au cours de la messe, et la distribution aux assistants par les servants de messe du « biscuit de saint Eldrad », qui clôt la cérémonie. Le « biscuit de saint Eldrad » n’est pas, comme je l'avais pensé dans un premier temps, le pain bénit ayant «la forme d'un cœur pour exprimer la grande charité du saint envers ses concitoyens » que mentionnait le chanoine Ollivier en commentant une des lettres du marquis de Jessé-Charleval ${ }^{99}$, mais un sablé sur lequel «autrefois » était figuré un serpent que «aujourd'hui » les pâtissiers ne savent plus faire ${ }^{100}$. Elles se situent dans le flou chronologique typique du discours sur les traditions. La lettre de l'abbé Michel permet de préciser quelque peu la chronologie. Ces biscuits bénits distribués par les servants de messe sont « des petits sablés spécialement confectionnés pour l'occasion par l'un ou l'autre des boulangers lambescains à [sa] demande ». Ils étaient "initialement de forme à évoquer un serpent, en référence au miracle, mais sont devenus au fil des années de simples sablés formés à l'emporte-pièce » ${ }^{101}$.

\section{Un concurrent : Ambel}

L'identification d'Ambelliacum avec Lambesc n'a pas convaincu le père Turinetti, qui a édité la Vie d'Eldrad dans les Acta sanctorum en $1668{ }^{102}$. Comme cette localité située "in Provincia" était dite proche des Alpes, il a été conduit à penser qu'il pourrait s'agir — mais à titre d'hypothèse — d'un village situé dans le val de l'Estéron, et d'autres, cherchant dans la même direction, ont proposé Beuil (Boglio). Or, comme le faisait remarquer en 1881 Paul Guillaume dans ses Recherches historiques sur les Hautes-Alpes, trois communes voisines portent aujourd'hui le nom d'Ambel, comme Ambel et Monestier-d'Ambel, dans le canton de

98. Ibid. Un poème publié le 20 mars 2010 par Vette de Fonclare, habitante de Lambesc, sur son blog Poèmes en Provence, en ligne à l'adresse http://poemes-provence.fr/la-saint-eldrad [site consulté le 24 août 2017], commente de façon sarcastique ce défilé :

$$
\begin{aligned}
& \text { C'est à la Saint-Eldrad qu'on bénit les chevaux, } \\
& \text { Les ânes, les moutons, les vaches et leurs veaux } \\
& \text { Et les chiens et les chats. Et pourquoi pas leurs puces? }
\end{aligned}
$$

En 2017 une prière en provençal, A saint Eldrade, patroun di pastre, a été lue au cours de la messe (information communiquée à l'auteur par Claire Laurent). Le texte ni signé ni daté, qui serait récent, est conservé aux archives diocésaines d'Aix et Arles. La bénédiction des chevaux est signalée également à Ambel, comme me l'a signalé le docteur Gérard Cardin.

99. Chan. F. Ollivier, 781-875, saint Heldrad, citoyen de Lambesc..., p. 18.

100. Ces informations ont été recueillies par Claire Laurent, ethnologue, qui s'est associée à mes recherches et a assisté à la fête en 2016 et 2017.

101. L'étude ici présentée demanderait à être complétée par une enquête orale, mais on mesure sur ce seul point les incertitudes de la mémoire.

102. Vita [sancti Heldradi, abbatis Novalitii]... 


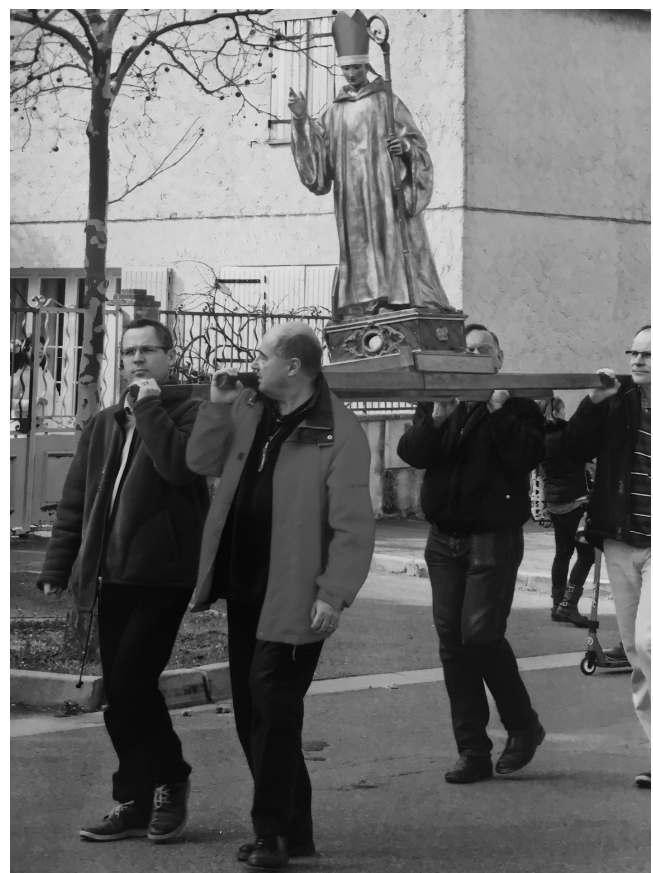

Fig. 3. - Fête de Saint-Eldrad à Lambesc (13 mars 2016), la statue du saint portée en procession. Cliché Claire Laurent.

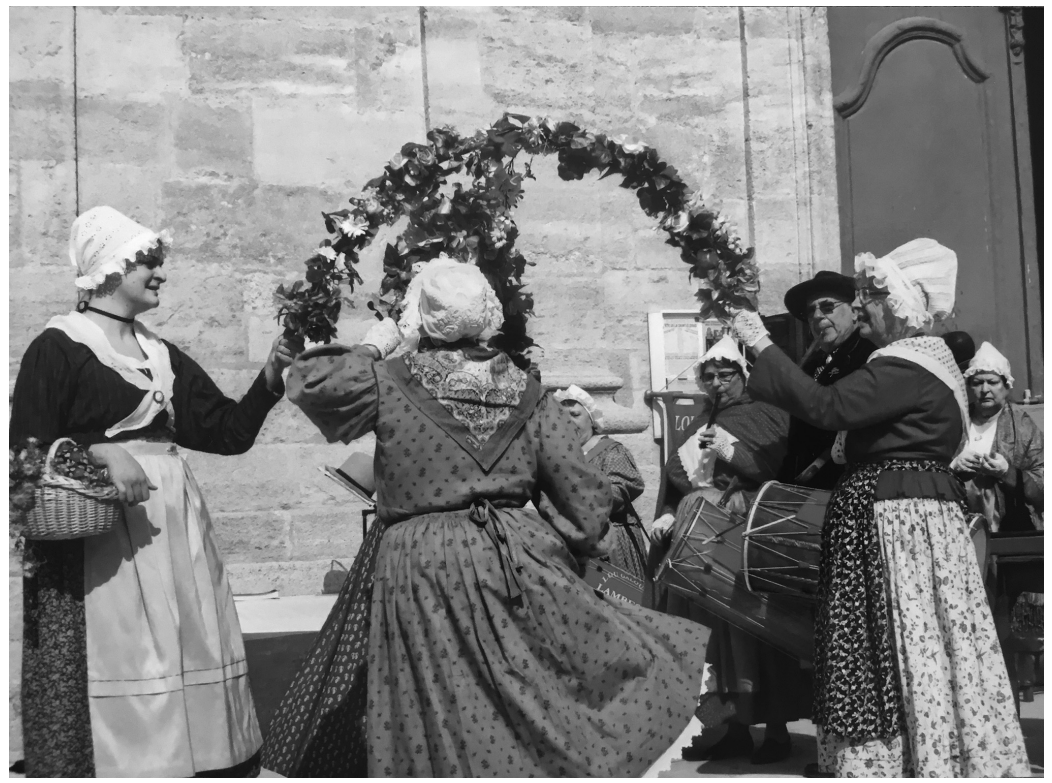

FIG. 4. - Fête de Saint-Eldrad à Lambesc (13 mars 2016), danses folkloriques exécutées par le groupe folklorique Lou Galoubet. Cliché Claire Laurent. 
Matheysine-Trièves, en Isère, et Clémence-d'Ambel, dans le canton de SaintFirmin, dans les Hautes-Alpes 103.

Un manuscrit conservé à la Bibliothèque nationale de France qui regroupe des comptes de décimes de différents diocèses du début du xvi ${ }^{\mathrm{e}}$ siècle mentionne en 1515 une "capella Sancti Eldradi in ecclesia de Ambello". C'est la première trace d'une dévotion à saint Eldrad en Dauphiné ${ }^{104}$. «Jusqu'ici aucun historien des Hautes-Alpes [...] ne s'est occupé de saint Eldrade, ni Fournier, ni le docteur Albert, ni le baron de Ladoucette, ni $\mathrm{M}^{\mathrm{gr}}$ Depéry en son Histoire hagiologique du diocèse de Gap, etc., etc. ", s'étonnait Paul Guillaume ${ }^{105}$, et on peut étendre sa remarque au département voisin de l'Isère. L'auteur rappelait que, selon sa Vita, saint Eldrad avait donné l'ordre à ses religieux d'aller dans la vallée de Briançon pour y élever des constructions pour les habitations des moines, «et ex abundantia cellarum Monasterium illum vocitarunt" ${ }^{106}$. Il notait que le culte de saint Eldrad existait encore au Monêtier-les-Bains et confessait ignorer si ce souvenir se conservait également à Ambel ${ }^{107}$.

Une cinquantaine d'années plus tard, le curé d'Ambel écrivait au frère Eldrad de l'abbaye de Hautecombe : «Le saint est inconnu des habitants de ma paroisse, où nul document à son sujet n'existe. Le culte du saint ne date que depuis l'approbation du propre de 1903. Nulle trace avant le $\mathrm{xx}^{\mathrm{e}}$ siècle [...]. Il n'existe pas d'image ${ }^{108}$." Cette affirmation est contredite par un témoignage manuscrit daté du 3 octobre 1999 recueilli par le docteur Gérard Cardin, de Corps, qui me l'a transmis récemment. Une de ses patientes y évoque le souvenir de son père, mis en nourrice à Ambel dans les années 1880. Cet homme trouva ensuite refuge chez le curé de ce village :

«Ce brave prêtre l'avait pris en amitié et il lui apprit à lire, écrire et compter et la dévotion à saint Eldrade. C'était aux années 1883. De ce fait mon père nous faisait invoquer le saint tous les jours à la fin de la prière du soir en famille ${ }^{109}$. "

103. Paul Guillaume, Recherches historiques sur les Hautes-Alpes, Paris, 1881, p. 73. D. W. Eyton, auteur d'un ouvrage dont le titre fait écho à ces propos, Un grand saint inconnu : saint Eldrad, son temps et son œeuvre (études de mours alpines), Paris, 1933, p. 4, relève, dans le catalogue du fonds de l'abbaye de Brema par Emmanuel Pilot de Thorey, la mention en 1448 d'un moine de Brema rector capelle Sancti Eldradi.

104. Le nom est absent de l'index de la thèse de Pierrette PARAvy, De la chrétienté romaine à la Réforme en Dauphiné : évêques, fidèles et déviants (vers 1340-vers 1530), Rome, 1993 (Coll. de l'École française de Rome, 183).

105. P. Guillaume, Recherches historiques sur les Hautes-Alpes..., p. 73. De son côté, D. W. Eyton, Un grand saint inconnu..., p. 20, relevait que, «tandis qu’à Aix et à Lambesc on travaillait à faire vivre le culte de saint Eldrad, dans le diocèse de Gap et dans les parties de ce diocèse qui appartiennent aujourd'hui au diocèse de Grenoble, saint Eldrad semblait totalement inconnu ".

106. P. Guillaume, Recherches historiques sur les Hautes-Alpes..., p. 80-81.

107. Ibid., p. 83 : "Le culte de saint Eldrade, nous dit-on, existe encore au Monêtier-deBriançon [...]. Nous ignorons si l'on conserve également à Ambel le souvenir de saint Eldrade.» 108. Cité par A. BAs, Eldrad, un saint lambescain..., p. 12.

109. Lettre du docteur Gérard Cardin à l'auteur, 3 juillet 2013. J'ai respecté l'orthographe du texte de Rose Biau. La mention " C'était aux années 1883 » semble avoir été rajoutée après coup. Rose Biau mentionne ensuite la guérison miraculeuse d'un cheval en 1937 après que le père, qui était resté à côté de l'animal couché incapable de se relever, eut demandé à ses enfants de prier saint Eldrad. Je remercie le docteur Cardin de m’avoir communiqué ce document. 
Dans sa lettre, le docteur Cardin affirmait : «Le culte à saint Eldrad est certain au $\mathrm{XIx}^{\mathrm{e}}$ siècle dans notre région ${ }^{110}$. " $\mathrm{Au} \mathrm{XIx}^{\mathrm{e}}$ siècle ? C'est peut-être beaucoup dire. Les témoignages de Paul Guillaume et de la patiente du docteur conduiraient à parler plutôt des dernières années de ce siècle. Les défenseurs de l'origine lambescaine du saint ne se font pas faute de rappeler, quant à eux, que, "à diverses époques, les moines de Novalèse vinrent à Lambesc chercher et vénérer les vestiges de leur grand abbé » et que, en particulier en juillet 1857, deux moines de cette abbaye firent le pèlerinage à pied de Novalèse à Lambesc ${ }^{111}$. Les archives paroissiales conserveraient une lettre de l'évêque de Suse rédigée en 1903 par laquelle ce prélat s'avouait "après pur examen convaincu que saint Eldrad est né à Lambesc " ${ }^{112}$. En outre, un petit livre publié en 1969, écrit par une habitante du Monêtier-lesBains, Gabrielle Sentis, confère à Auguste Pascal, curé du lieu entre 1919 et 1937, un rôle comparable à celui du curé Aubert de Lambesc :

"Mais ici-bas tout s'oublie : le prieuré ayant disparu au dix-huitième siècle, le souvenir du saint abbé allait faire de même si l'abbé Pascal, curé du Monêtier, n'avait pas entrepris de le faire revivre. Il se mit en rapports avec l'abbaye bénédictine de Hautecombe, où le frère Eldrade, au nom prédestiné, put lui obtenir une relique et tous les renseignements pour écrire une petite brochure actuellement épuisée ${ }^{113}$."

Ce texte racontait l'histoire oubliée de la fondation sur ce site d'un prieuré de la Novalaise à l'instigation de l'abbé Eldrad. Mais a-t-il suffi à ancrer le souvenir d'Eldrad et de la Novalaise dans le village ? On peut en douter en lisant dans une brochure publiée en mars 1997 qu’ «au fil des siècles Le Monêtier oublia son fondateur. Jusqu'au jour de 1994 où le club des aînés Les Épis d'or, avec l'aide de l'archevêché [sic] de Gap, de l'abbaye de la Novalaise, de la paroisse, de la mairie et des habitants du Monêtier, décida de le sortir de l'oubli ${ }^{114}$. "

La brochure de l'abbé Pascal de 1924 était aussi un livre de combat. Dès sa première page et la première note du texte, on pouvait y lire : « Nous demeurons fidèle à la tradition millénaire qui fait naître Eldrad à Lambesc contre les nouvelletés qui placent son berceau à Ambel ${ }^{115}$. " Le 23 mars de la même année, un auteur anonyme se permettait de mettre en doute, dans la Semaine religieuse de l'archidiocèse d'Aix, les certitudes localement établies :

«Il faut bien reconnaître que la position d'Ambel, dominée par la Salette, le Valgodemar et le Dévoluy, répond mieux que le site de Lambesc à la description que les

110. Lettre du docteur Gérard Cardin à l'auteur, 3 juillet 2013.

111. C'est le cas de Élie Roussier, conservateur-archiviste des Amis du Vieux Lambesc, dans une lettre adressée le 19 mai 1954 à l'administrateur de la vie diocésaine à Aix (archives diocésaines d'Aix et Arles, dossier «Lambesc »), qui reprend des arguments avancés avant lui par le frère Eldrad.

112. Ibid. Joseph Peyre, curé de Lambesc, avait répondu à ses recherches de précisions sur le pays d'origine du saint en lui adressant un mémoire rédigé par le frère Eldrad.

113. Gabrielle Sentis, Monêtier-les-Bains : essai sur un village des Hautes-Alpes, suivi d'une Vie de saint Eldrade, son fondateur, Grenoble, 1969, p. 86 . Voir la n. 66 ci-dessus.

114. Paul Engilberge, Saint Eldrade: un monastère, un miracle et quatre chapelles au Monêtier, 1997. Pourtant l'abbé Pascal avait, selon G. Sentis, Monêtier-les-Bains..., p. 86, poussé "le zèle jusqu'à introniser une statue, hélas bien sulpicienne, [d'Eldrad] dans l'église ".

115. [Abbé A. PAscal], Saint Eldrade et le Monêtier-les-Bains..., p. 1. 
auteurs nous font du pays où naquit notre saint. Le «flumen Desaudorausum », qui est dit le traverser, serait, d'après les chartes locales du xıII ${ }^{\mathrm{e}}$ et xIv $^{\mathrm{e}}$ siècle, le Drac, le fougueux affluent de l'Isère ${ }^{116}$."

L'hebdomadaire se sentit tenu d'insérer une réponse cinglante du frère Eldrad, qui affirma que Lambesc est «à cheval sur des collines boisées, enceintes elles-mêmes par les Alpes des Bouches-du-Rhône », et déclara qu'Ambel, "simple possession matérielle de l'abbaye, est à peine mentionné dans leur cartulaire [celui des moines de Novalaise]", de même que Monestier-d'Ambel, "que les "Nouvellistes" veulent faire remonter à saint Heldrad, n’a jamais été un monastère, mais seulement un bien-fonds de l'abbaye de Novalèse " ${ }^{117}$. Trente ans plus tard, une lettre du conservateur du musée du Vieux Lambesc proclame le même attachement «à la tradition millénaire qui fait naître saint Eldrad à Lambesc contre les Nouvellistes qui placent son berceau à Ambel " ${ }^{118}$.

Même les auteurs dauphinois qui revendiquent le saint pour leur pays acceptent des éléments de la tradition lambescaine. Gabrielle Sentis, qui restitue à Eldrad la fondation du Monêtier et le miracle des serpents, commence son résumé de la vie du saint en écrivant qu' «il naît en 781 [...] au château d'Ambolia, aujourd'hui Lambesc (Bouches-du Rhône), où un autel lui a été consacré dans l'église paroissiale. Mais une autre tradition le ferait naître à Ambel (Isère), où un autel lui fut également consacré en $1516^{119}$. " Elle reproduit les noms que le frère Eldrad avait attribués aux parents du saint, et en fait, comme lui, des Burgondes, ariens à l'origine, mais convertis à la foi catholique. Cette partie de la légende dorée élaborée à Lambesc survit d'ailleurs toujours en Dauphiné. Ainsi, une brochure publiée en mars 1997 par la paroisse du Monêtier-les-Bains situe l'enfant né à Ambel dans la descendance du «comte Byzardon, seigneur de Lambesc», qui reçut ce territoire de Charles Martel "en l'an 732, après la victoire de Poitiers ", lorsque le vainqueur "récompense ses capitaines burgondes». Elle donne pour père à cet enfant Ardrad, "capitaine burgonde comme son père, le comte Byzardon ", et pour mère "son épouse, Leodda ", qui "lui donnent pour nom Heldrad (héros prudent) et comme prénom Pierre " ${ }^{120}$. Un dépliant, publié en août 2008, Découvrir saint Eldrade, qui associe de manière œcuménique Novalèse, Ambel, Corps, Lambesc, Monestier-d'Ambel et Le Monêtier-les-Bains, indique que, "lorsque Charles Martel divisa la France entre ses grands capitaines après la bataille de Poitiers en 732, le territoire d'Ambel et Corps fut adjugé à un noble seigneur de Provence

116. [Chan. François Trouche], "Éphémérides des saints de Provence ", dans Semaine religieuse de l'archidiocèse d'Aix, 23 mars 1924 [rééd. Éphémérides des saints de Provence, Raphèle-lès-Arles, 1992], p. 171-172, à la p. 171.

117. "Éphémérides des saints de Provence : une mise au point ", dans Semaine religieuse de l'archidiocèse d'Aix, 4 mai 1924, p. 246-248, aux p. 247-248. La réponse adressée par le frère Eldrad était bien plus longue et virulente, comme on peut le voir dans les archives conservées à Ganagobie (voir la n. 66 ci-dessus).

118. Voir la n. 111 ci-dessus.

119. G. Sentis, Monêtier-les-Bains..., p. 64.

120. Voir les n. 70 et 71 ci-dessus. 
[exeunt les Burgondes!] dont le petit-fils devait devenir célèbre : saint Eldrad »; elle affirme que «dans l'église bâtie [à Lambesc] de 1700 à 1741 fut englobée une partie du palais des aïeux de saint Eldrade " ${ }^{121}$. L'auteur d'un livre sur les sanctuaires du Trièves paru en 1980 juxtapose des affirmations peu conciliables en écrivant :

«Depuis un temps immémorial, saint Eldrad était honoré spécialement à Ambel. Il était né à Lambesc (Provence) en 785. Son père était le seigneur du lieu [...]. Une chapelle fut créée à son honneur à Ambel, mentionnée depuis 1516. Il existait aussi la croix de saint Eldrad. Le jour de la fête du saint (13 mars), on disait la messe le matin, puis, l'après-midi, les fidèles se rendaient en procession à la croix, un usage observé jusqu'en $1957^{122}$."

Cette querelle de clochers peut sembler enterrée. D. W. Eyton le notait déjà : «Aujourd'hui ce zèle sacré s'est heureusement calmé, et les habitants de Lambesc aussi bien que ceux d'Ambel défilent processionnellement le 3 mars autour de leur village respectif à l'ombre de la bannière de saint Eldrad sans chercher à savoir si le saint est bien né chez eux ou non ${ }^{123}$. " Bien plus, le 26 octobre 1996, Georges Righetti, secrétaire de l'association Les Épis d'or, dont la brochure de 1997 soulignait le rôle dans la redécouverte de saint Eldrad au Monêtier-les-Bains, écrit en tant que «chargé des initiatives Saint Eldrad » à l'évêque [sic] d'Aix pour proposer que, «pour la première fois, les différentes localités que saint Eldrad unit, Lambesc, berceau de sa famille, Ambel, où il vit le jour, Le Monêtier-les-Bains, où il réalisa le miracle des serpents, et Novalèse, où il fut abbé », se retrouvent pour fêter le saint les 10 et 11 mai 1997. Une petite note jointe, rédigée en accord avec Daniel Blin, président du comité Saint Eldrad de Lambesc, propose un programme pour ces journées. Le samedi sera consacré « au marché à l'ancienne, aux anciens métiers et aux danses des groupes folkloriques ». La messe du dimanche, concélébrée et au cours de laquelle chaque délégation chantera son cantique à saint Eldrad, sera suivie de la bénédiction des chevaux. Le rédacteur ajoute qu' " au centre de la fête il y aura les moutons, car saint Eldrad est le patron des bergers ». L'après-midi sera "marquée par le défilé des attelages et les danses des groupes folkloriques ». Une étape ultérieure est prévue : "La décision d'organiser ensemble en 1998 un colloque sur saint Eldrad à l'abbaye de Novalèse pourrait être prise ${ }^{124}$. » Effectivement, une « journée internationale d'études sur saint Eldrade » s'est tenue à l'abbaye de la Novalaise le 29 août 1998, devant un public venu du Monêtier-les-Bains, de Monestier-d'Ambel, d'Ambel, de Corps et de Lambesc ${ }^{125}$.

121. Ce document, comme le précèdent, m’a été aimablement communiqué par le docteur Gérard Cardin.

122. Aimé Beaup, Les sanctuaires du Trièves : églises, temples, chapelles, Marseille, 1980, p. 293.

123. D.W. Еутом, Un grand saint inconnu..., p. 17.

124. Archives diocésaines d'Aix et Arles, dossier "Lambesc ".

125. Deux communications y furent présentées, l’une du docteur Gérard Cardin, «Saint Eldrade et l'école théologique de Lyon au Ix ${ }^{\mathrm{e}}$ siècle ", l'autre du père Réginald Grégoire, o.s.b., professeur à l'université d'Urbino, «Saint Eldrade, entre légende et histoire ». 
Réconciliation ou paix armée ? La parution en 2008 de la brochure d'Alix Bas intitulée Eldrad, un saint lambescain, qui affiche dans son titre sa position tranchée dans « la controverse qui nous oppose à nos amis d'outremont ", est rédigée, on le voit, sur un ton plus modéré que les philippiques du frère Eldrad, mais l'auteur n'y présente pas moins une « défense de la tradition ", dont elle " accepte toutes les contraintes » ${ }^{126}$. Elle l'enrichit en faisant dériver Ambolia d'ambulare, "marcher" (d'où le sens de marché !), et cherche à situer cet oppidum sur le plateau de San-Peyre, en dépit de son exiguïté, de la pauvreté en vestiges archéologiques sur place, qui ne peuvent pas dater du haut Moyen Âge et qui ne peuvent être identifiés avec le village détruit en 1222. Consciente du caractère aventureux de ces conjectures, elle trouve dans les graffiti de la table d'autel d'Auriol, postérieurs à la jeunesse d'Eldrad, "l'élément probant qui [lui] manquait » et la raison de continuer le combat ${ }^{127}$.

\section{Pour aller au-delà de cette controverse}

Cette querelle de clocher est-elle justifiée ? Les travaux les plus récents sur le monastère de la Novalaise, en éclairant les circonstances de la construction de l'image historiographique de l'abbé Eldrad, conduisent à en douter ${ }^{128}$.

À une époque que l'on ne peut situer qu'approximativement, les moines de l'abbaye fondée par le patrice Abbon en 726 ont abandonné le site de la Novalaise pour s'implanter à Turin à côté d'une église dédiée à saint André. Le Chronicon Novaliciense explique leur départ par l'incursion de Sarrasins venus du Freinet. Mais on sait le peu de crédit qu'il convient d'accorder à ce topos de l'histoire de la Provence et des Alpes. Assez vite, ils ont abandonné Turin pour s'établir une centaine de kilomètres plus à l'est, à Brema, près de Pavie. Vers l'an mil, l'abbé de Brema envoie un certain nombre de moines réoccuper la Novalaise, qui devient un prieuré de son monastère. Cette abbaye rénovée s'efforce par la suite de prendre pied au nord des Alpes et en Provence, où se situaient les domaines légués par Abbon. C'est dans ce contexte que les moines de Brema s'emploient à promouvoir, sans doute dès le $\mathrm{IX}^{\mathrm{e}}$ siècle, mais avec plus d'ampleur aux $\mathrm{XI}^{\mathrm{e}}$ et $\mathrm{xII}^{\mathrm{e}}$ siècles, le culte de saint Eldrad. L'analyse très convaincante des textes alors produits pour relater la vie d'Eldrad que développe Laurent Ripart invite à "prêter attention à leur volonté de souligner les origines provençales de l'abbé Eldrad,

126. A. BAs, Eldrad, un saint lambescain..., p. 12 et 19. On n'est pas surpris de voir que cette fidélité à la tradition s'étend à la croyance en l'apostolicité des Églises de Provence (voir ibid., p. 28, la mention des rives de l'Huveaune foulées par Marie-Madeleine à la recherche d'un asile).

127. Ibid., p. 17-19 et 27-28.

128. Sur l'abbatiat d'Eldrad, l'essentiel des informations est fourni par Luigi Provero, "L'abbaziato di Eldrado a Novalesa e il confronto con la società valsusina (secolo Ix) ", dans Bolletino storico-bibliografico subalpino, t. 99 (2001), p. 381-404. 
qui, dans cette perspective, peut être considéré comme un saint voué à la reconquête des terres transalpines de la Novalaise » ${ }^{129}$. Il poursuit :

«Toutes les sources hagiographiques écrites par les moines de la Novalaise et de Breme s'accordent en effet non seulement pour insister sur sa naissance en haute Provence, mais aussi pour localiser en ces lieux l'un des miracles majeurs dont il était censé être l'auteur.

"La Vie de saint Eldrad, que l'on peut sans doute, dans son état final, dater du $\mathrm{XII}^{\mathrm{e}}$ siècle, bien que sa première partie soit probablement plus ancienne, commence ainsi par exposer que "le bienheureux Eldrad est issu d'une importante famille de la patrie gallicane, qui est appelée Provence, et, comme on le dit de source sûre, du château d'Ambel". Si les sources ne permettent pas de vérifier l'authenticité de cette tradition, il semble en tout cas manifeste que l'insistance des hagiographes à situer le lieu de naissance d'Eldrad dans leurs domaines de haute Provence, au cœur de l'une des principales seigneuries que le patrice Abbon leur avait léguées en 739 , relève d'un travail de réélaboration mémorielle destiné à valoriser le patrimoine transalpin de leur abbaye. Tout aussi significative fut la volonté des hagiographes de localiser l'un des principaux miracles d'Eldrad dans le diocèse de Briançon [sic pour Gap], au sein de laquelle [sic] le saint abbé aurait providentiellement libéré la vallée de l'actuel Monêtier-les-Bains des serpents qui l'infestaient. Selon la Vie de saint Eldrad, le saint abbé aurait décidé après ce miracle d'y envoyer certains de ses frères qui "trouvèrent ce lieu si propice à l'habitation des moines qu'ils y bâtirent des églises, y construisirent des bâtiments et, en raison de son grand nombre de cellules, l'appelèrent le Monêtier (monasterium)". En jouant sur l'étymologie du Monêtier, la Vie de saint Eldrad donnait ainsi au patrimoine que les moines de la Novalaise y possédaient une nouvelle importance, en affirmant que le saint abbé y avait jadis établi un prieuré, ce qui semble bien peu crédible, puisque de tels essaimages, très caractéristiques de la période féodale, sont en revanche inhabituels à l'âge carolingien ${ }^{130}$. "

\section{On doit penser avec l'auteur que :}

«Les toponymes en monasterium qui se sont développés au Monestier-d'Ambel ou au Monêtier-les-Bains correspondent sans doute bien davantage à une tradition qu'à une réalité : malgré les dires de la chronique de la Novalaise, qui y situe d'anciennes communautés monastiques, il n'existe en ces lieux aucune attestation archivistique ou archéologique qui pourrait témoigner de la présence d'un ancien prieuré. Le chartrier de la Novalaise ne laisse d'ailleurs guère de place au doute, puisqu'il ne comporte pas la moindre trace d'un quelconque prieuré que les moines de la congrégation de Breme auraient alors pu édifier en Provence ${ }^{131}$. "

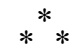

Ainsi, la personne de l'abbé Eldrad fut, à deux reprises, à l'origine de l'invention d'une tradition. Une première fois au Moyen Âge central pour

129. Laurent RIPART, "L'abbaye de la Novalaise et son patrimoine provençal », dans Bulletin de la Société d'études des Hautes-Alpes, 2015, p. 63-76, à la p. 73. Voir aussi ID., "La Novalaise, les Alpes et la frontière (viII ${ }^{\mathrm{e}}$-xiI ${ }^{\mathrm{e}}$ siècle) ", dans Frederi Arneodo et Paolo Guglielmotti (éd.), Attraverso le Alpi, San Michele, Novalesa, S. Teofredo e altri reti monastiche: atti del convegno internazionale di studi (Cervére-Valgrana, 12-14 marzo 2004), Bari, 2008 (Biblioteca Michaelica, 3), p. 95-114. Le travail de création d'un "passé mythique» par le moine qui a constitué le Chronicon Novaliciense a été finement étudié par P. J. GEARy, Mémoire et oubli à la fin du premier millénaire, trad. fr., [Paris], 1996 (Histoires Aubier), p. 171-184.

130. L. Ripart, «L'abbaye de la Novalaise... », p. 73.

131. Ibid., p. 75. 
servir aux prétentions sur la Provence du monastère qu'il dirigea au $\mathrm{Ix}^{\mathrm{e}}$ siècle. Une seconde fois au XviII ${ }^{\mathrm{e}}$ siècle pour fonder dans un village de basse Provence une forme durable de religion civique. Cette seconde vie de saint Eldrad devrait inciter à poursuivre au-delà du XviI siècle l'étude de cette forme de culte sur laquelle André Vauchez a, à juste titre, attiré l'attention ${ }^{132}$.

\section{Noël Coulet,}

université d'Aix-Marseille, laboratoire «Temps, espaces, langages, Europe méridionale-Méditerranée ».

132. André VAuchez (éd.), La religion civique à l'époque médiévale et moderne (chrétienté et islam) : actes du colloque, Nanterre, 21-23 juin 1993, Rome, 1995 (Coll. de l'École française de Rome, 213). Parmi les communications présentées lors de ce colloque, deux seulement se sont aventurées au-delà de la fin du $\mathrm{XvI}^{\mathrm{e}}$ siècle. 